\title{
Constitutively active FOXO1a and a DNA-binding domain mutant exhibit distinct co-regulatory functions to enhance progesterone receptor $A$ activity
}

\author{
Michael D Rudd, Ignacio Gonzalez-Robayna ${ }^{2}$, Inmaculada Hernandez-Gonzalez ${ }^{1}$, \\ Nancy L Weigel, William E Bingman III and JoAnne S Richards \\ Department of Molecular and Cellular Biology, Baylor College of Medicine, One Baylor Plaza, Houston, Texas 77030, USA \\ ${ }^{1}$ Departments of Biochemistry and Molecular Biology and ${ }^{2}$ Physiology, Faculty of Sciences, University of Las Palmas, 35017 Las Palmas, Grand Canaria, Spain \\ (Requests for offprints should be addressed to J S Richards; Email: joanner@bcm.tmc.edu)
}

\begin{abstract}
FOXO (Forkhead box $\mathrm{O} 1$ transcription factors) factors interact with and modify the activity of other transcription factors, including nuclear hormone receptors. However, not all of the structural domains within the FOXO proteins that mediate these functional interactions have been clearly defined. To address this issue, we used a constitutively active (nuclear) mutant of FOXO1a (designated FOXOA3) and within FOXOA3 made additional mutations to alter the putative nuclear hormone interacting domain (NID), minimal activation domain (MAD), DNA-binding domain (DBD), and the N terminus. We document that FOXOA3 enhanced the hormone-dependent transcriptional activity of liganded progesterone receptors $A$ (PGRA) on a glucocorticoid response element-responsive promoter, PGRA on the insulin-like growth factorbinding protein 1 promoter, and estrogen receptor $\alpha$ on an estrogen response element-responsive promoter. The effects of FOXOA3 on PGRA were dependent, in part, on an intact NID, the MAD, and N-terminal domain. In striking contrast, a FOXOA3 DNA-binding mutant (FOXOA3-mDBD) modulated PGRA, PGRB, and ESR1 activities by distinctly different mechanisms, markedly elevating ligand-independent activity of these nuclear hormone receptors even in the double mutant lacking the MAD. Furthermore, both FOXOA3 and FOXOA3-mDBD enhanced the activity of a transcriptionally defective PGRA lacking its AF1 transactivation domain, indicating that this region of the receptor is not essential in this context. Since FOXOA3, FOXOA3-mDBD, and FOXOA3-mNID all bound PGRA in a GST pull-down assay, it appears that the LXXLL (leucine-X-X-leucine-leucine) motif within the NID is not critical for FOXOA3 interactions with PGRA, but may modify the recruitment of other co-regulatory molecules. Collectively, the results show that FOXOA3 exerts co-regulatory functions independent of DNA binding and that the DNA-binding defective form of FOXO1a is transcriptionally active as a co-regulator of these nuclear hormone receptors.
\end{abstract}

Journal of Molecular Endocrinology (2007) 38, 673-690

\section{Introduction}

Members of the forkhead family of transcription factors regulate many key biological processes (Burgering \& Kops 2002, Accili \& Arden 2004). FOXO1a (FKHR), FOXO3a (FKHRL1), and FOXO4 (AFX) have received much attention due to their important and highly conserved role in the insulin-like growth factor (IGF) signaling cascades of Caenorhabditis elegans and mammals (Kops et al. 1999, 2002, Nakae et al. 2001, Richards et al. 2002b, Kenyon 2005). In this pathway, FOXO transcription factors are downstream targets of AKT/PKB (protein kinase B), SGK (serum- and glucocorticoid-regulated-kinase), and other kinases and upon phosphorylation are excluded from the nucleus (Brunet et al. 1999, 2001, Nakae et al. 2001, Richards et al. 2002b). Since FOXO factors play key regulatory roles in suppressing cell cycle progression (Ramaswamy et al. 2002), their exclusion from the nucleus provides one mechanism by which cells can increase their proliferative activity (Van der Heide $e t a l$. 2005). Functional regions within the FOXO proteins have been identified by various approaches and include the DNA-binding domain (DBD) and the minimal activation domain (MAD; Bennicelli et al. 1995, Schuur et al. 2001). These have been characterized extensively in regards to FOXO activity on promoters containing the consensus FOXO-binding sites or insulin response sequence (IRS) in genes, such as IGF-binding protein 1 (Igfbp1; Schuur et al. 2001), p21Cip1 (Prowse et al. 1997), and p27Kip (Medema et al. 2000, Kim et al. 2005).

However, the functions FOXO factors are more complex. In addition to their ability to bind DNA and regulate gene transcription, these factors have also been observed to function as co-regulators of other transcription factors (Ramaswamy et al. 2002). For example, FOXOla, like FOXH1 (originally named FAST; foxo activin signal transducer), interacts with members of the 
SMAD (MAD homolog) transcription factor family that are targets of the bone morphogenic protein (BMP) family of signaling molecules (Seoane et al. 2004), whereas FOXH1 and SMAD2 interact via their C-terminal domains, and FOXO1a and SMAD3 interact via their N-terminal domains. More recently, FOXO factors have been shown to impact the activity of $\beta$-catenin and vice versa (Essers et al. 2005). Of interest to investigators studying various endocrine-related functions, metabolism and cancer (Kodama et al. 2004), FOXO factors have been shown to interact with numerous nuclear hormone receptors (AR (androgen receptor), ER $\alpha$, PR (progesterone receptor), GR (glucocorticoid receptor), CAR (Nr1i3; nuclear hormone receptor subfamily 1 , group I, member 3 ), RAR (retinoic acid receptor), PXR (peroxisome receptor), PPAR $\gamma$ (peroxisome proliferation activator receptor gamma), TR (thyroid hormone receptor), HNF-4 (hepatic nuclear transcription factor 4); Schuur et al. 2001, Zhao et al. 2001, Hirota et al. 2003, Li et al. 2003, Hang et al. 2004) and co-activators PGC1 $\alpha$ (Puigserver et al. 1998, 2003, McKenna \& O'Malley 2002) and co-regulatory molecules such as CBP (CREB binding protein)/P300 (Van der Heide \& Smidt 2005) to regulate promoter activity of genes involved in metabolism and cell cycle progression. Since FOXO factors have a conserved, consensus LXXLL motif that is a docking site for nuclear hormone receptors in other co-regulatory molecules (Heery et al. 2001), this domain has been presumed to mediate FOXO interactions with nuclear receptors (Zhao et al. 2001). However, this has not been experimentally tested. Nor has the functional role of the FOXO1a MAD been tested as a mediator of FOXO effects on nuclear hormone receptor activity. Since FOXO factors have been shown to exert repressor as well as co-activator activity on nuclear receptors, the specific regions of FOXO factors that mediate these effects need to be clearly defined.

Since FOXO factors are excluded from the nucleus by phosphorylation of three key serine/threonine residues (Brunet et al. 1999, 2001), a constitutively active (nuclear) form of FOXO1a has been generated by mutation of these residues to alanine, yielding the A3 mutant of FOXO (FOXOA3; Ramaswamy et al. 2002). This form of FOXOla has been used in many types of functional studies (Accili \& Arden 2004). Moreover, gene profiling analyses determined that the defective DNA-binding mutant (H215R substitution) of FOXOA3 exhibits functional activities that are both similar to as well as distinct from those of FOXOA3 in an in vivo (cell culture) system (Ramaswamy et al. 2002). For example, FOXOA3 regulates specific genes to block cell cycle progression and to induce apoptosis. The DBD mutant failed to regulate genes involved in apoptosis but retained the ability to block cell cycle progression. Despite these observations that provide functional evidence that some actions of FOXO occur independently of its ability to bind directly to DNA and that the DBD mutant is active as transcriptional co-regulator, the mechanisms by which this DBD mutant acts on nuclear receptors or other transcription factors to regulate gene expression remain largely unexplored.

Based on these considerations, the goals of the studies presented herein were to determine which regions of the FOXOla protein impact its regulation of nuclear hormone receptor activity. For these studies, we used progesterone receptor A (PGRA), a FOXOA3, and a consensus glucocorticoid response element/ progesterone responsive element (GRE/PRE) promoter reporter construct as a simplified model system. Specific FOXOA3 mutants, including the mutants of the DBD, putative nuclear hormone interacting domain (NID), and MAD were generated to define regions of the FOXOla protein that are critical for functional interactions with PGRA on the minimal consensus GRE/PRE promoter. To a lesser extent, but as a comparison, we tested FOXO interactions with estrogen receptor $\alpha$ (ERS1) on an estrogen response element (ERE)-containing promoter. The more complex Igfbpl promoter that is regulated by both the PGRA and FOXO (Gao et al. 1999, 2000, Kim et al. 2005) was also analyzed. Lastly, since FOXOla is highly expressed in ovarian granulosa cells (GC; Richards et al. 2002b, Shi \& LaPolt 2003, Cunningham et al. 2004, Park et al. 2005) and appears to impact IGF1- and follicle stimulating hormonemediated functions of GC (Gonzalez-Robayna et al. 2000, Richards et al. 2002a,b Park et al. 2005), we analyzed the activity of selected vectors in this cell system as well.

\section{Materials and methods}

\section{Animals}

Immature female Sprague-Dawley rats (Harlan Inc., Indianapolis, IN, USA) were housed under $16 \mathrm{~h}$ light:8 h darkness schedule in the Center for Comparative Medicine at Baylor College of Medicine (BCM) and provided with food and water ad libitum. Animals were treated in accordance with the NIH guide for the Care and Use of Laboratory Animals as approved by the Animal Care and Use Committee of BCM.

\section{Cell culture}

COS-1 cells (simian fibroblast cells (CV-1 cells) transformed with SV (simian virus) 40 viral genome) were obtained from the Cell Culture Core Facility (Department of Molecular and Cellular Biology) and grown at $37^{\circ} \mathrm{C}, 5 \cdot 0 \% \mathrm{CO}_{2}$, in Dulbecco's modified Eagle's Medium 
(DMEM) plus $10 \%$ fetal bovine serum. Cells for experiments to test the transcriptional activity from an ERE-luciferase were plated in DMEM containing charcoal-stripped serum and lacking phenol red. GC were harvested from estrogen-primed $(1.5 \mathrm{mg}$ estradiol $/ 0.2 \mathrm{ml}$ propylene glycol/day $\times 3$ days) rats and cultured as previously described on serum-coated plates in serum-free defined medium (Fitzpatrick \& Richards 1991, Sriraman et al. 2003).

\section{Plasmids}

pALTER-MAX-FKHRWT, containing the cDNA for HA-tagged WT FOXOla, and pALTER-MAXFKHRA3, containing the same cDNA but with alanine substitutions for Threonine 24, Serine 256, and Serine 319 (the 'A3 mutation') were gifts from Dr Terry Unterman (University of Illinois at Chicago College of Medicine). pcDNA3-FKHR;HRAAA, containing the cDNA for FLAG-tagged FOXOla with alanine substitutions for Threonine 24, Serine 256, and Serine 319 as well as an arginine substitution for Histidine 215 was a gift from Dr William Sellers (Harvard Medical School). The GRE $_{2}$-TATA-Luc reporter plasmid, the PSCT (expression plasmid containing the SV40 origin of replication, the CMV (cytomegalovirus) promoter and the T7 promoter along with the cDNA of interest) expression vector, and the PSCT-PGRA construct (PSCT containing the cDNA for PGRA) were gifts from Dr Rainer Lanz and Dr Neil McKenna (Baylor College of Medicine). The 3xIRS-Luc reporter plasmid was a gift from Dr Eric D Tang (University of Michigan Medical School), and the pVit ERE-Luc reporter plasmid was a gift from Dr V Craig Jordan (Northwestern University Feinberg School of Medicine).

The parent plasmid pShuttle-XR was fabricated from pShuttle (BD Biosciences Clontech) by inserting a fragment created from the annealed oligonucleotides $5^{\prime}$ CTAGCGGTACCAGTACTGGATCCGATATCTCTAGAGTAC $3^{\prime}$ and $5^{\prime}$ TCTAGAGATATCGGATCCAGTACTGGTACCG $3^{\prime}$ into NheI/KpnI digested pShuttle, thereby reversing the orientation of the multiple cloning site within pShuttle and changing some of the unique sites. pShuttle-XR-FKHRWT and pShuttle-XR-FKHRA3 were created by inserting a KpnI/EcoRV digestion fragment of pALTER-MAX-FKHRWT or pALTER-MAXFKHRA3, containing the cDNA for HA-tagged wild type or HA-tagged A3 mutant FOXO1a respectively into KpnI/EcoRV-digested pShuttle-XR. pShuttle-XR9FKHRA3-mDBD was created by exchanging the BlnI/ SgrAI fragment from pShuttle-XR9-FKHRA3 for its equivalent in pALTERMAX-FKHRAAA;HR.

pShuttle-XR-FKHRA3-mNID was assembled by first digesting pShuttle-XR-FKHRA3 with Spe I and then self-ligating the larger digestion product. The resulting construct, pShuttle-XR9-FKHRA3Spe, contained a unique Nde I site within the cDNA insert. A fragment containing the desired mutated NID motif was then fabricated by overlapping the PCR amplification of pShuttle-XR9-FKHRA3, using the primer pair $5^{\prime}$ GGAGACTCTCACCCATTATGACCGAACAGGATG $3^{\prime}$ and $5^{\prime}$ AAGTCACCACECTCCTTCAAGAGTCCAGGCGCACAG $3^{\prime}$ to generate one of the preliminary fragments and using the primer pair $5^{\prime}$ AGGTGGTGACTTCTGACTCTCCTCCCCATAATGAC $3^{\prime}$ and $5^{\prime}$ ATGTCACAGTCTAAGCGCTCAATGAACATGC $3^{\prime}$ to generate the other (the underlined nucleotides introduce $\mathrm{L} 465 \mathrm{~V}$ and L466V mutations into the final product). The overlapping PCR product was then digested with BsrGI and NdeI for insertion into similarly digested pShuttleXR-FKHRA3delSpe, and an MfeI/BamHI fragment from pShuttle-XR-FKHRA3 was substituted for the $\mathrm{MfeI} / \mathrm{BamHI}$ fragment in pShuttle-XR-FKHRA3delSpe to restore the SpeI fragment that had initially been excised from pShuttle-XR-FKHRA3 and thereby create pShuttle-XR-FKHRA3-mNID.

pShuttle-XR-FKHRA3-delMAD and pShuttleXR-FKHRA3-mDBD-delMAD were derived from pShuttle-XR-FKHRA3 and pShuttle-XR-FKHRA3mDBD respectively by digestion with PvuII and EcoRV, followed by self-ligation.

pShuttle-XR9-FKHRA2delC and pShuttle-XR9FKHRA2delC-mDBD were created by replacing an EcoRV/BlnI digestion fragment from each of those vectors with the annealed oligonucleotides $5^{\prime}$ CTAGGAGAAGAGCTGCAGCCATGGACAACAACTGAGAT $3^{\prime}$ and $5^{\prime}$ ATCTCAGTTGTTGTCCATGGCTGCAGCTCTTCTC $3^{\prime}$.

pShuttle-XR9-FKHRA2-delNH and pShuttle-XR9FKHRA2-delNH-mDBD were both assembled from the intermediate construct pShuttle-XR9-FKHRA2FP. Preliminary fragments for use in an overlapping PCR were amplified from pShuttle-XR9-FKHRWT by PCR with the primer pair $5^{\prime}$ GGGAGGTCTATATAAGCAGAGCTCTC $3^{\prime}$ and $5^{\prime}$ TTCTTCACGTGGAAAGCGTAATCTGGAACATC $3^{\prime}$ and with the primer pair $5^{\prime}$ ACGCTTTCCACGTGAAGAATTCAATTCGTC $3^{\prime}$ and $5^{\prime}$ GTACTCCAGTTATCAAAGTCATCATTGCTGTG. The product from the overlapping PCR was then digested with BlnI and BamHI for ligation into corresponding sites in pShuttle-XR9-FKHRA3 to make pShuttle-XR9FKHRA2FP. A segment that was next amplified by PCR from pShuttle-XR9-FKHRA3 or pShuttle-XR9-FKHRA3mDBD, using primers $5^{\prime}$ AACACGTGCGCAAGAGCAGCTCG $3^{\prime}$ and $5^{\prime}$ GTACTCCAGTTATCAAAGTCATCATTGCTGTG $3^{\prime}$, was digested with BlnI and PmlI for insertion into pShuttle-XR9-FKHRA2FP to create pShuttle-XR9-FKHRA2-delNH or pShuttle-XR9-FKHRA2delNH-mDBD respectively.

pShuttle-PGRA-myc was created as previously reported (Sriraman et al. 2005). 
The mouse IGFBP-1 luciferase reporter construct pGL3-mIGFBP1 was created by first amplifying a segment of the mouse IGFBP-1 promoter (Accession no. X67493;+466 thru +877) from genomic DNA by the PCR, using the primers $5^{\prime}$ TTACTAGTTCTGTTCTTTCTTTAGTCGCTTAGG $3^{\prime}$ and $5^{\prime}$ GTAGATCTCAATGGTGGTCACAGCTC $3^{\prime}$. The amplicon, which contained a 52 bp insert at +813 of the sequence reported under Accession no. X67493, was then digested with SpeI and BglII for ligation into NheI/ BglII-digested pGL3-Basic.

\section{Luciferase reporter assays}

Cells were plated in 12-well dishes at $5 \cdot 0 \times 10^{4}$ cells $/$ well (COS- 1 cells) or at $1 \cdot 0 \times 10^{6}$ cells/well (primary GC; Sriraman et al. 2003). All transfections were performed in triplicate with Fugene 6 (Roche) as prescribed by the manufacturer, using $500 \mathrm{ng} /$ well of the indicated reporter plasmid, $50 \mathrm{ng} /$ well of pRL-TK (Promega), the indicated amount/well of other vectors, and a 3:1 ratio of Fugene 6:total plasmid. Empty expression vectors for PGRA or ERS1 and for the FOXO1a mutants were added as necessary to equalize the total amount of plasmid transfected per well. Unless otherwise indicated, 36-48 $\mathrm{h}$ after transfection, the cells were treated for $4 \mathrm{~h}$ with $10 \mathrm{nM}$ R5020, $100 \mathrm{nM}$ estradiol, or vehicle (ethanol) and then lysed with buffer containing $200 \mathrm{mM}$ Tris $(\mathrm{pH} 7 \cdot 5)$ and $0 \cdot 1 \%$ Triton X. Firefly and Renilla luciferase assays were conducted separately on the lysate from each well.

\section{PGRA-GST pull-down assays}

Adenovira vectors expressing FOXOA3 and FOXOA3mDBD were gifts from Dr William Sellers (Harvard Medical School). FOXOA3-mNID was created according to the protocol for the BD-Adeno-XTM Expression System (BD Biosciences Clontech) using pShuttle-XR9FOXOA3-mNID as the shuttle construct. To obtain cells expressing significant amounts of FOXOA3, FOXOA3 DBD mutant, and FOXOA3 NID mutant proteins, adenoviral vectors were expanded and tested to verify the absence of replication competence adenovirus according to established procedures and with the assistance of the Vector Core Laboratory at Baylor College of Medicine (Dr Alan R Davis, Director; http://vector.bcm.tmc.edu). COS cells, infected with adenoviral vectors at moi15:1, and expressing the indicated FOXOA3 proteins, were harvested and cell extracts prepared in lysis buffer ( $50 \mathrm{mM}$ Hepes $(\mathrm{pH} 7 \cdot 5)$,

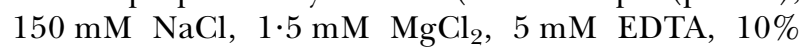
glycerol, $1 \%$ Triton X-100, $100 \mathrm{mM} \mathrm{NaF}, 1 \mathrm{mM}$ $\mathrm{Na}_{3} \mathrm{VO}_{4}, 10 \mathrm{mM} \mathrm{Na}{ }_{4} \mathrm{P}_{2} \mathrm{O}_{7}$, and $0.5 \%$ Sigma protease inhibitor cat \# P8340). To minimize Triton X-100 in the incubations, the lysates were diluted at a ratio of $1: 10$ in TEDGN (10 mM Tris (pH 8.0), $1 \mathrm{mM}$ EDTA, $1 \mathrm{mM}$ dithiothreitol (DTT), $10 \%$ glycerol, $100 \mathrm{mM} \mathrm{NaCl}$ ) containing $1 \mathrm{mg} / \mathrm{ml}$ BSA immediately prior to use. Extract from Sf-9 cells expressing recombinant GSTPGRA (obtained from the Protein Core Laboratory at Baylor College of Medicine; Dr Dean Edwards, Director) was dialyzed against $20 \mathrm{mM}$ Tris (pH 7.8), $50 \mathrm{mM} \mathrm{NaCl}$, $10 \%$ glycerol, $1 \mathrm{mM}$ DTT, and $1 \mathrm{mM}$ phenylmethylsulphonyl fluoride and clarified by centrifugation. The dialyzed extract was diluted at a ratio of $1: 10$ with TEDGN (10 mM Tris (pH 8.0), 1 mM EDTA, 1 mM DTT, $10 \%$ glycerol, $100 \mathrm{mM} \mathrm{NaCl}$ ) containing $1 \mathrm{mg} / \mathrm{ml}$ BSA. Diluted extract $(0.5 \mathrm{ml}$ containing an estimated $2 \mu \mathrm{g}$ GST PGRA) was incubated with $40 \mu \mathrm{l}$ of a 1:1 slurry of glutathione sepharose beads (GE/Amersham) in TEDGN in siliconized Eppendorf tubes. Control glutathione sepharose beads were incubated with $2 \mu \mathrm{g}$ GST in $1 \mathrm{mg} / \mathrm{ml}$ BSA in TEDGN. Beads were washed with TEDGN to remove unbound protein. PGRA-bound or control GST-bound beads were then incubated with $0.5 \mathrm{ml}$ diluted FOXO1 extracts for $1 \mathrm{~h}$ at $4^{\circ}$ on a rotating shaker, washed four times with TEDGN, transferred to fresh tubes, and washed two additional times prior to extraction with $40 \mu \mathrm{l}$ of $2 \times$ SDS sample buffer. The eluted factors were analyzed by western blotting with the FOXO-specific antibody.

\section{Statistical analyses and computations}

All statistical computations were performed with Microsoft Excel 2000 software. Results were compared for statistical significance using a two-sample, equal variance (homoscedastic) Students $t$-test returning two distribution tails and setting the threshold of significance at $P<0 \cdot 05$.

\section{Results}

\section{FOX01a mutants differ widely in their ability to activate a reporter containing an IRS}

A diagram of FOXO1a and each mutant that was tested in this study appears in Fig. 1A. FOXOA3 bears an alanine substitution for each of the three residues targeted by PKB, thereby ensuring its retention in the nucleus (reviewed in Burgering \& Kops 2002). All other mutants herein were derived from FOXOA3, each when expressed in COS cells was localized to the nucleus and expressed at similar levels (data not shown). Specific mutations were generated by mutating the putative NID (from LXXLL to LXXAA), by deleting the carboxy-terminal MAD and by using the DBD mutant with the H215R substitution. Double mutants were also generated as indicated. In addition, 


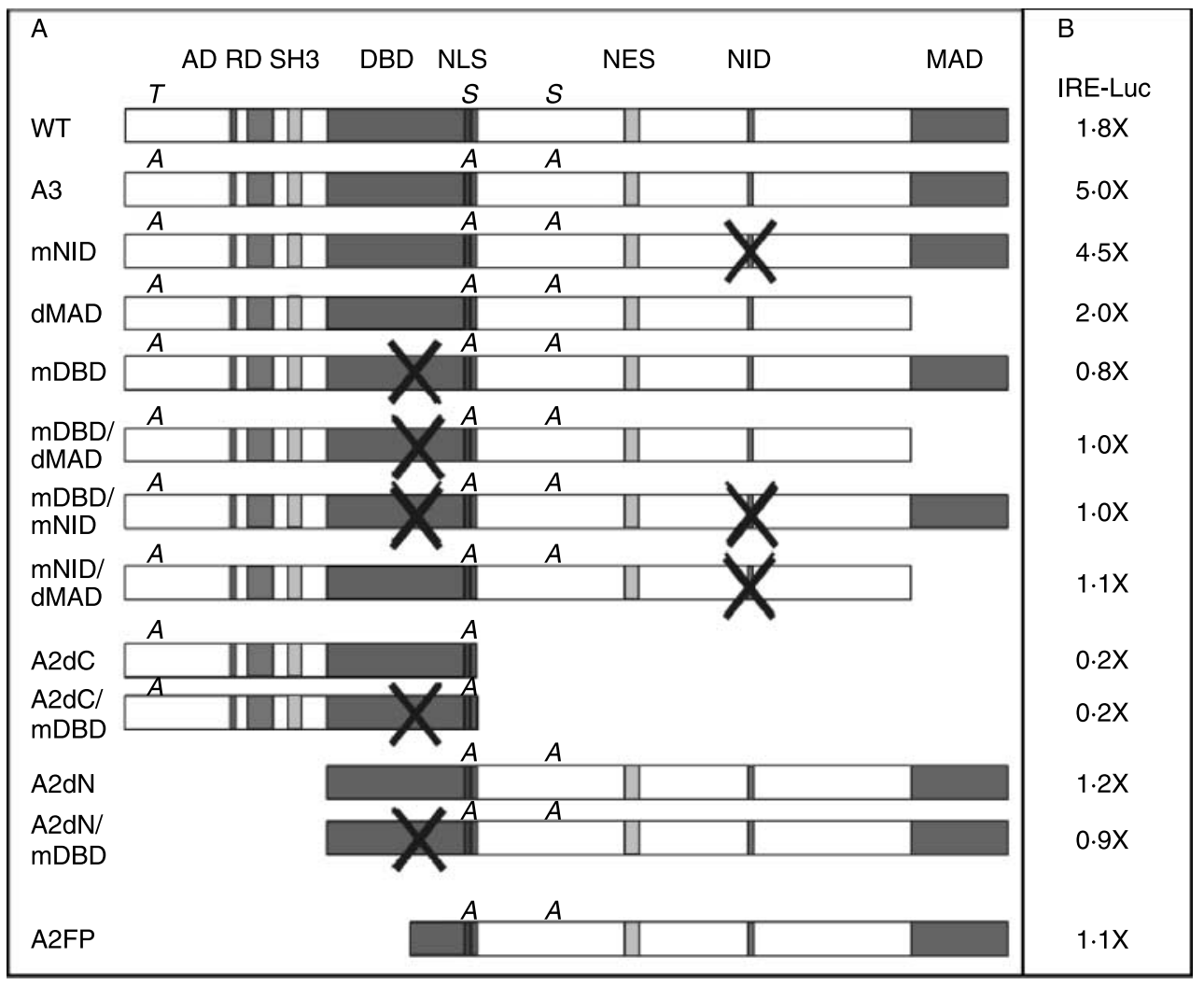

Figure 1 Schematic of FOXO constructs and activity on an IRS-driven promoter. (A) A structural diagram of wild-type FOXO1a and the different mutants used in this study is shown. Drawn to scale within the primary structure is the location of the acidic domain (AD), putative repressor domain (RD), potential $\mathrm{SH} 3$ domain (SH3), DNA-binding domain (DBD), nuclear localization signal motif (NLS), nuclear export signal motif (NES), putative nuclear hormone receptor interaction domain (NID), and minimal activation domain (MAD). Cross marks signify domains disrupted through point mutation. (B) Summarized is the transactivational ability of the various mutants, measured by a 3xIRS-luciferase reporter. COS cells were co-transfected in 12-well dishes with a 3xIRS-luciferase reporter (500 ng/well) plus a constitutively active Renilla expression vector ( $50 \mathrm{ng} /$ well), and with either an empty vector or with constructs (100 ng/well) expressing FOXO1a (WT), FOXOA3 (constitutively active FOXO1a), or FOXOA3 mutants. Forty hours after transfection, cell lysates were prepared and frozen for later assaying. Luciferase activity relative to Renilla is presented as fold induction over that from the empty vector.

$\mathrm{N}$-terminal and carboxy-terminal deletion mutants were generated with or without a mutated DBD.

The transactivational activity of each mutant was tested by co-transfecting an expression vector of each one and a 3xIRS-luciferase reporter construct into COS cells. FOXOA3 and FOXOA3-mNID were functionally active $(P<0 \cdot 001)$, relative to the activity of an empty expression vector (Fig. 1B), whereas wild-type FOXOla and FOXOA3 with a deleted MAD (FOXOA3-dMAD) were minimally active $(P<0.05)$ and all others were inactive $(P>0 \cdot 05$; Fig. 1B).

\section{FOXO1a and PGRA functionally interact on a PGR- responsive promoter}

Having obtained and generated the structural and functional mutants described in Fig. 1, we next explored which regions of FOXO1a were critical for its interactions with the nuclear hormone receptors, using PGRA and, to a lesser extent, ERS1 as simplified model systems. The effects of FOXO1a on the functional activity of PGRA were examined by co-transfecting FOXOA3, PGRA, or both, and a PGR-responsive GRE-luciferase reporter construct into COS cells. As shown (Fig. 2: lanes 2 and 3), FOXOA3 alone had negligible activity, but the addition of the ligand R5020 caused a slight increase in the luciferase activity, suggesting that COS cells have a factor that not only recognizes a GRE but also responds more strongly in the presence of FOXOA3. Transfection of PGRA dramatically induced ligand-dependent, but not ligand-independent, promoter activity (lane 4 compared with lane 1), confirming earlier observations (Zhao et al. 2001, Doyle et al. 2004). Moreover, when increasing amounts of FOXOA3 were co-expressed with PGRA, each 
A

GRE-Luc

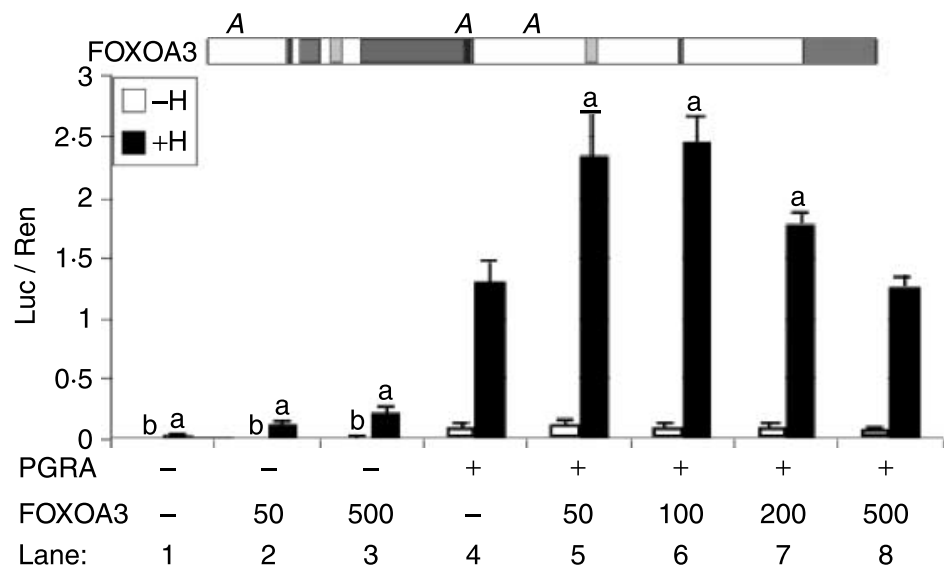

B

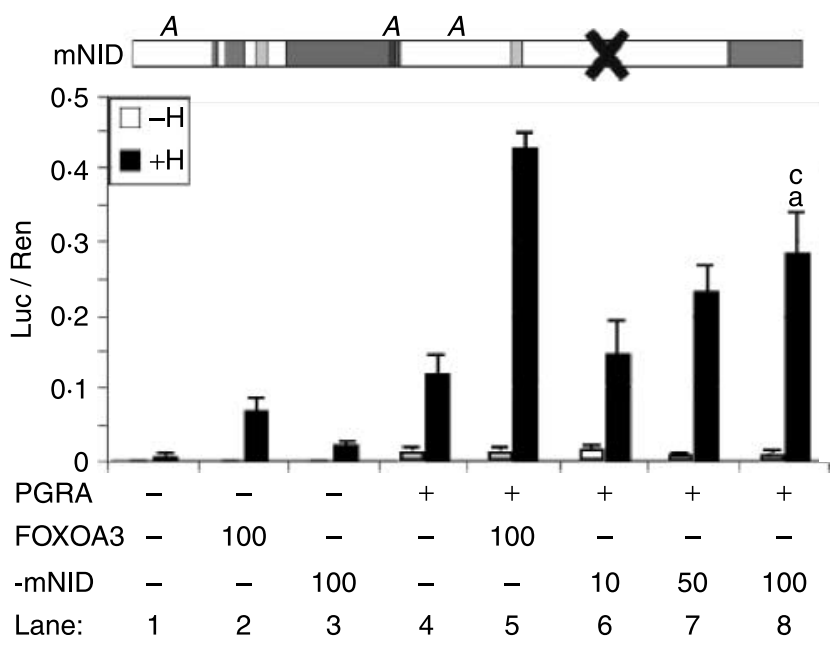

C

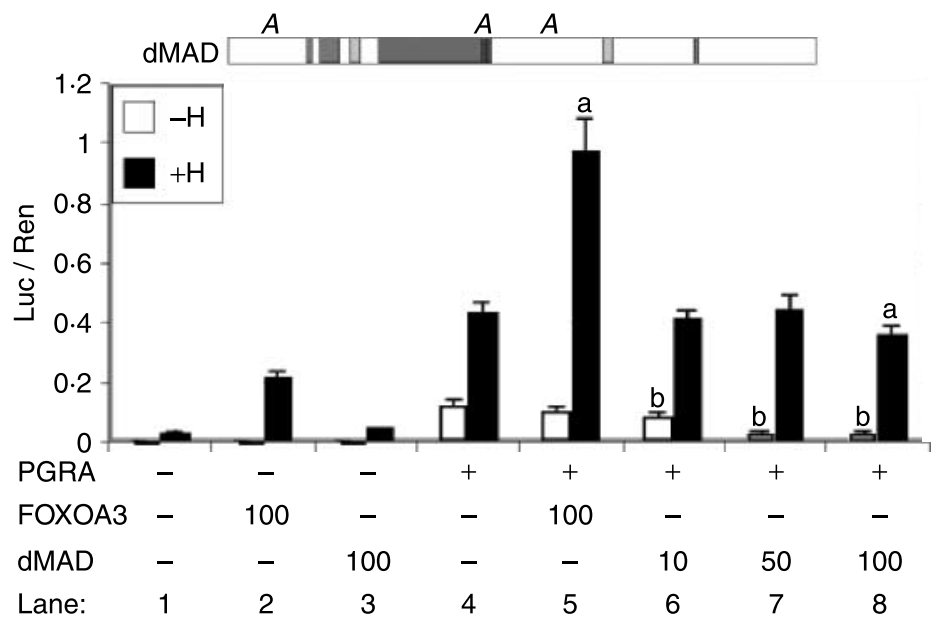


but the highest dose enhanced hormone-dependent activation of the GRE-luciferase promoter (lanes 5-8, compared with lane 4) without altering hormoneindependent activation (lanes 5-8, compared again with lane 4). FOXOA3 also enhanced ERS1 activation of an ERE-responsive reporter (data not shown; Fig. 2). Thus, in this context, FOXOA3 can enhance liganded PGRA and ERS1 transactivation potential.

Conversely, when increasing concentrations of PGRA $(10,50,100 \mathrm{ng})$ were co-transfected with either FOXOA3 or FOXOA3-NID, activation of the IRE-Luc promoter-reporter construct by these FOXO factors was reduced significantly $(P<0 \cdot 05$; data not shown $)$ by PGRA in a dose-dependent and partially hormonedependent manner, confirming studies of others that nuclear hormone receptors can impact the function of FOXO1a (Schuur et al. 2001).

\section{Interactions of FOXO1a and PGRA are partly depen- dent on the NID and MAD}

Since the LXXLL motif has been presumed, but not tested, to be critical for FOXOla interactions with nuclear hormone receptors (Heery et al. 2001, Schuur et al. 2001, Zhao et al. 2001), we next examined the role of the putative nuclear hormone receptor interaction domain (NID; LXXLL) by mutating this region to LXXAA in FOXOA3 (FOXOA3-mNID; Fig. 1). When FOXOA3-mNID and PGRA were co-transfected, this mutant was capable of enhancing hormone-dependent PGRA activity over twofold (Fig. 2B: lane 8 compared with lane 4), but was much less potent than FOXOA3 (Fig. 2B: lane 8 compared with lane 5). FOXOA3-mNID also reduced ESR1 activation of an ERE-promoter (data not shown). These results document that the NID impacts the ability of wild-type FOXO1a to modulate PGRA and ESR1 activity but is not the sole region of FOXO necessary for functional interacts.

Deleting the MAD at the $\mathrm{C}$ terminus of FOXO1a eliminated all but a very low level of FOXOla transactivation activity on IRS-containing promoters (Fig. 1, Bennicelli et al. 1995). However, the extent to which the MAD supports the function of FOXOla as a co-regulator has not been reported. As shown in Fig. 2C, FOXOA3 but not FOXOA3-dMAD enhanced hormone-dependent PGRA activation (lane 5 compared with lane 4; lanes 6-8, compared with lane 4). Furthermore, the dMAD mutant repressed hormone-independent PGRA activity in a dosedependent manner (lanes 6 through 8, compared with lane 4), suggesting that this mutant acts as a dominant negative variant for unliganded PGRA. Thus, the MAD is more essential than the NID for FOXOA3 to enhance PGRA activity.

\section{The DBD mutant of FOXOA3 strongly enhances PGRA and ERS1 activity with or without hormone}

The FOXO DBD mutant (FOXOA3-mDBD) is frequently used to show that it is an inactive mutant of FOXOla at least on IRS promoters (Tang et al. 1999). However, since this same mutant can regulate the expression of specific genes (Ramaswamy et al. 2002, Park et al. 2005), we explored whether the DBD mutant could affect PGRA activation of the GRE-luciferase reporter. When FOXOA3-mDBD was co-transfected with PGRA, it enhanced the hormone-dependent activity of PGRA beyond that seen with FOXOA3 (Fig. 3A, lanes 6-8 compared with lane 5). Surprisingly, this mutant also stimulated ligand-independent PGRA activity to the same level (lanes 6 through 8). Furthermore, whereas addition of a PGR antagonist RU486 blocked FOXOA3 enhancement of PGRA activation of luciferase, this compound failed to alter either ligand-dependent or -independent activation of PGRA by FOXOA3mDBD (data not shown).

In a similar manner, when a vector expressing ESR1 was co-transfected into COS cells with FOXOA3 or FOXOA3mDBD, each enhanced ligand-dependent ESR1 activation of an ERE luciferase reporter (Fig. 3B, lane 5 compared with lane 4; lanes 6-8 compared with lane 4 respectively). In addition, FOXOA3-mDBD was more potent than FOXOA3 in increasing the ligand-independent activity of ESR1 (lanes 7 and 8 compared with lane 5). Collectively, these data indicated that the DBD mutant can activate PGRA and ESR1 in ways that are clearly distinct from those by which FOXOA3 functions and appears to mimic ligand activation.

\section{The effects of FOXO1a on PGRA depend on the length of hormone treatment}

An earlier observation that FOXO1a represses PGRA activity (Zhao et al. 2001) was obtained after a $24 \mathrm{~h}$ incubation with hormone rather than after the $4 \mathrm{~h}$ incubation used throughout this study. This suggested

Figure 2 Ligand-dependent PGRA activation of a PRE/GRE-Luc construct is enhanced by FOXOA3 and reduced or eliminated by NID and MAD mutants respectively. COS cells were co-transfected with a PRE/GRE-luciferase reporter plasmid and a constitutively active Renilla expression vector as described in the Materials and methods. Also included were $10 \mathrm{ng} /$ well of a PGRA expression construct, and the indicated amounts (ng/well) of FOXOA3 (A), FOXOA3-mNID (B), or FOXOA3-dMAD (C) expression vectors. A day and a half later, cells were treated for $4 \mathrm{~h}$ with vehicle (open bars, $-\mathrm{H}$ ) or the PR agonist R5020 $(10 \mathrm{nM}$; solid bars, $+\mathrm{H})$ and lysed. Luciferase assay data are presented as the mean \pm s.E.M. (Firefly luciferase activity relative to Renilla). (A) ' $a$ ' and ' $b$ ' indicate a significant difference from the respective $+\mathrm{H}$ and $-\mathrm{H}$ values in lane 4; (B) ' $a$ ' and ' $c$ ' indicate a significant difference from the $+\mathrm{H}$ values in lanes 4 and 5 respectively. (C) 'a' and 'b' indicate a significant difference from the respective $+\mathrm{H}$ and $-\mathrm{H}$ values in lane 4 . 


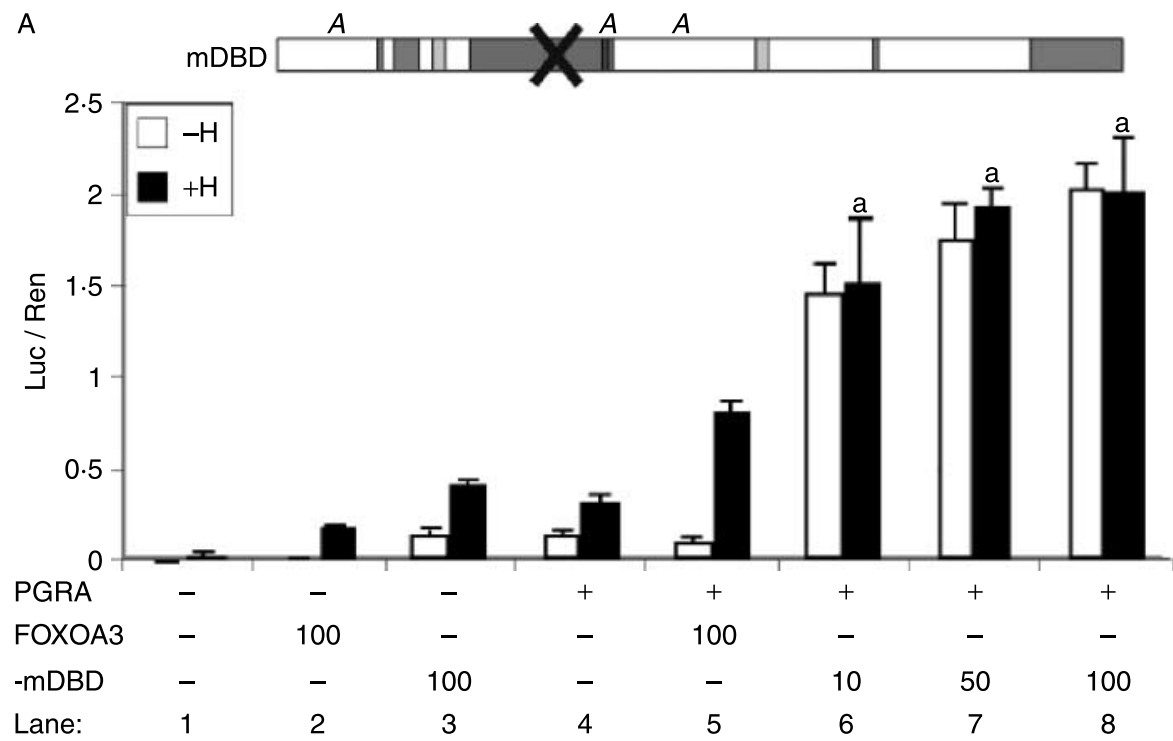

B

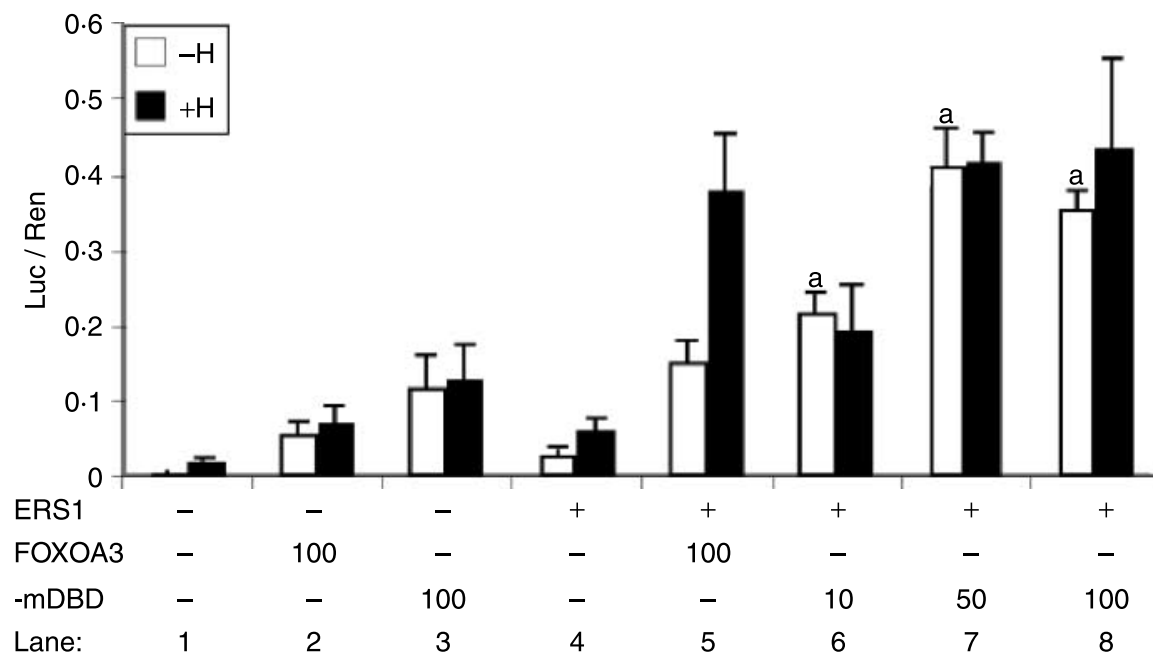

Figure 3 A mutant of FOXOA3 bearing the H215R mutation in its DNA-binding domain enhances both the ligand-independent and the ligand-dependent activities of PGRA and ERS1. COS cells were co-transfected as in Fig. 2 with a GRE reporter construct, a Renilla expression plasmid, and a PGRA (A) or ERS1 (B) expression plasmid (10 ng/well) as indicated, and an expression plasmid in the amounts shown (ng/well) for one or more of the specified FOXO1a mutants. A day and a half later, the cells were given a $4 \mathrm{~h}$ treatment with vehicle (open bars in each panel), R5020 (10 nM; solid bars in A), and estradiol (100 nM; solid bars in B). Luciferase assay data are displayed as in Fig. 2. (A) ' $a$ ' indicates a significant difference from the $+\mathrm{H}$ value in lane 5 . (B) ' $a$ ' indicates a significant difference from the $-\mathrm{H}$ value in lane 5 .

that the effect of FOXO1a on PGRA might also depend on the duration of hormone treatment. Therefore, a comparison was made for each of the two periods by co-transfecting the GRE-Luc construct with PGRA alone or in the presence of FOXOA3 or FOXOA3-mDBD. To permit the duration of vector expression to be the same in each treatment (i.e. $40 \mathrm{~h}$ total), hormone was added either $4 \mathrm{~h}$ (at $35 \mathrm{~h}$ ) or $24 \mathrm{~h}$ (at $16 \mathrm{~h}$ ) prior to lysate preparation. After $4 \mathrm{~h}$ treatment with hormone, the activity from a GRE construct was threefold higher in COS cells exogenously expressing both PGRA and FOXOA3 than in cells expressing only PGRA (Fig. 4, lane 3 when compared with lane 2). However, after $24 \mathrm{~h}$ the hormonedependent reporter activity from cells expressing only PGRA was nearly five times higher (Fig. 4, lane 2 compared with lane 6), indicating increased luciferase activity. Hormone-dependent activity from cells also overexpressing FOXOA3 was the same at the two time 
GRE-Luc

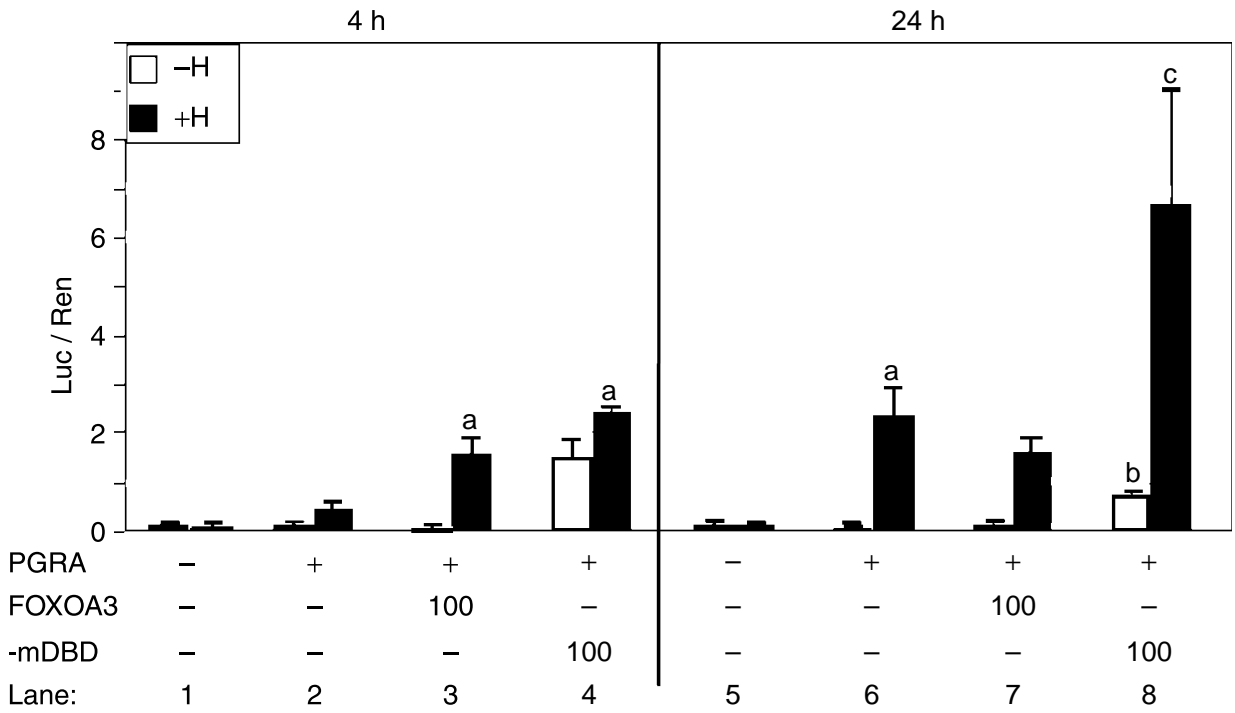

Figure 4 The effects of FOXOA3 and FOXOA3-mDBD on PGRA activity are time-dependent. COS cells were co-transfected as in Fig. 2 with a GRE reporter construct, a Renilla expression plasmid, a PGRA expression plasmid where indicated (10 ng/well), and an expression plasmid for FOXOA3 or FOXOA3-mDBD in the amounts (ng/well) shown. R5020 (10 nM; solid bars, $+\mathrm{H}$ ) or vehicle (empty bars, $-\mathrm{H}$ ) was added $4 \mathrm{~h}$ (lanes $1-4$ ) or $24 \mathrm{~h}$ (lanes $5-8$ ) before cell lysate preparation, and the same total time (one and a half days) was allowed between transfection and lysate preparation in each case. Luciferase assay data are presented as in Fig. 2. 'a' indicates a significant difference from the $+\mathrm{H}$ value in lane 2, 'b' indicates a significant difference from the $-\mathrm{H}$ value in lane 4 , and ' $c$ ' indicates a significant difference from the $+\mathrm{H}$ value in lane 4 .

points (lane 3 compared with lane $7 ; P>0 \cdot 05$ ). Therefore, the ultimate effect of FOXO1a on PGRA activity may be to accelerate the acute, rather than elevate the chronic, response of PGRA to hormone.

The effects of FOXOA3-mDBD on the PGRA activation of the GRE-luciferase vector were also time-dependent. In COS cells overexpressing both FOXOA3-mDBD and PGRA, reporter activation at $4 \mathrm{~h}$ in the absence of ligand was increased tenfold (Fig. 4, lane 4 compared with lane 2) and was nearly equal to that in the presence of ligand (lane 4). Similarly, at $24 \mathrm{~h}$ ligand-independent activation of PGRA by FOXOA3-mDBD was still observed (lane 8) though it was slightly lower than at $4 \mathrm{~h}$ (lane 8 compared with lane 4 ), whereas ligand-dependent activation of PGRA by FOXOA3-mDBD was highest at $24 \mathrm{~h}$ (lane 8 compared with lane 4). Thus, FOXOA3-mDBD seems to elevate PGRA activation of the GRE-luciferase construct in COS cells more persistently and to a higher chronic level than FOXOA3, suggesting that it may form a more stable complex and/or recruit specific transcriptional co-factors at $24 \mathrm{~h}$.

\section{FOXOA3, FOXOA3-mNID, and FOXOA3-mDBD bind directly to PGRA}

To determine if FOXOA3, FOXOA3-mDBD, or the FOXOA3-mNID mutant proteins could interact directly with PGRA protein, adenoviral vectors expressing each of these mutants were generated and used to infect COS cells. Cell lysates prepared from the infected cells were mixed with PGRA-GST-expressed protein for use in a GST pull-down assay. Cells infected with each adenoviral vector expressed high amounts of FOXO protein as revealed by western blotting with a FOXO-specific antibody (Fig. 5, lanes 1-3). However, all three FOXOA3 proteins bound to the PGRA-GST but not to GST (lanes 4-9). These results provide the first documentation that the putative nuclear receptor interacting domain (LXXLL motif) of FOXOA3 is not essential for FOXO1a binding to PGRA and that other regions of the protein are involved.

\section{The effects FOXOA3-mDBD on PGRA activity depend partly on the NID but not MAD}

Since the NID and MAD domains were critical for full activation of PGRA by FOXOA3, we next determined if these domains contributed to the function of the DBD mutant by generating double mutants (FOXOA3$\mathrm{mDBD} / \mathrm{NID}$ and FOXOA3-mDBD/dMAD). When FOXOA3-mDBD/NID was co-transfected with PGRA, it showed ligand-independent activity (Fig. 6A lanes 6 through 8, compared with lane 4) as does FOXOA3DBD mutant (Fig. 3A), but was less potent than FOXOA3 in enhancing the ligand-dependent activation of PGRA 


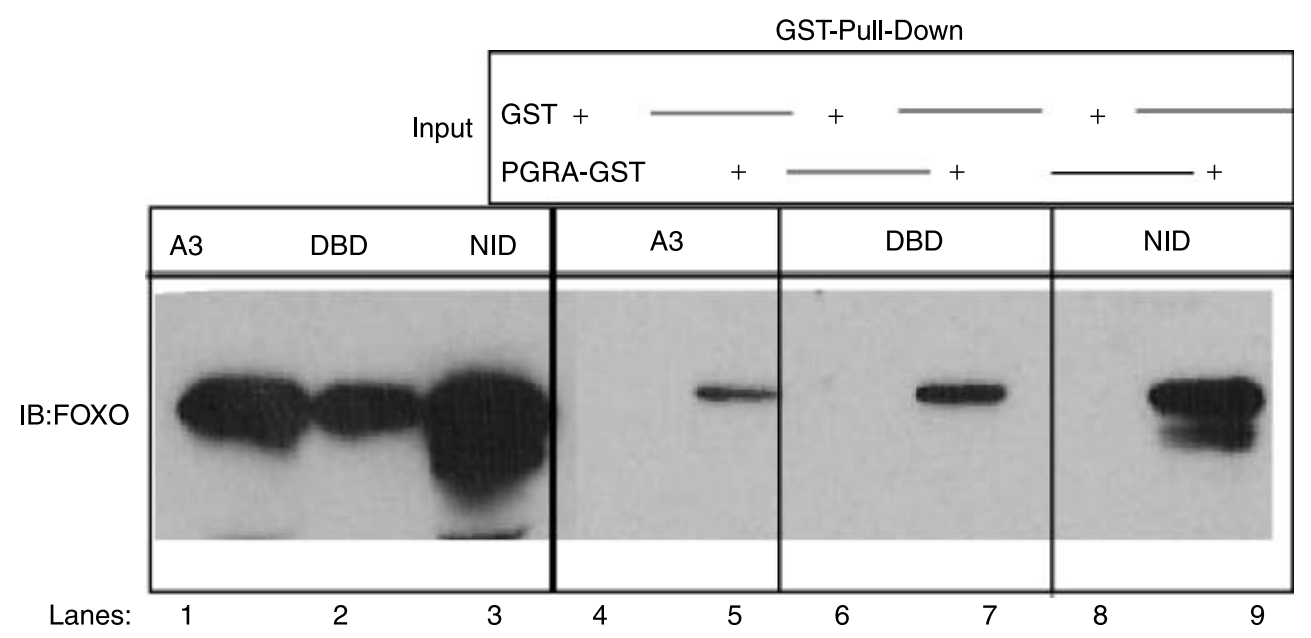

Figure 5 FOXOA3, FOXOA3-DBD, and FOXOA3-NID mutant proteins bind PGRA. COS cells were infected with adenoviral vectors (moi 15:1) expressing FOXOA3, FOXOA3-DBD, and FOXOA3-NID mutant proteins for $24 \mathrm{~h}$. Cell lysates were prepared and mixed with PGRA-GST or GST in a GST pulldown assay as described in Materials and methods. Western blots using a FOXO1a-specific antibody (1:1000) show the relative expression of FOXO in the diluted cell lysates $(2.5 \%$ of input; lanes $1-3)$ and demonstrable and highly specific FOXO protein binding following incubation with and elution from PGRAGST. FOXOA3 (lanes 5) and FOXOA3-mDBD (lane 7) as well as FOXOA3-mNID (lane 9) selectively bound PGRA-GST when compared with GST controls (lanes 4, 6, and 8). The experiment was repeated three times with similar, reproducible results.

(Fig. 6A, lanes 6 through 8 compared with lane 5). Therefore, the NID contributes partly to FOXOla interactions with PGRA, but is not the sole mediator of these interactions. In marked contrast, a double mutant lacking the MAD and bearing a disrupted DBD (FOXOA3-dMAD/mDBD) mimicked the DBD mutant. Specifically, this double mutant enhanced not only the hormone-dependent but also the hormone-independent activity of PGRA (Fig. 6B, lanes 6 through 8, compared with lane 4). These results show that the stimulatory effects of FOXOA3-mDBD on PGRA occur independently of the MAD but require the NID.

\section{Ligand-independent activation of PGRA by FOXOA3- $m D B D$ resides primarily in the $D B D$ and in the region between the DBD and the MAD}

Since the functional interactions of FOXOA3mDBD with PGRA appeared to occur even in the absence of the MAD, additional mutants that lacked the $\mathrm{C}$ terminus (FOXOA2dC; FOXOA2dC-mDBD) or the $\mathrm{N}$ terminus (FOXOA2dN; FOXOA2dN-mDBD) were generated and analyzed. FOXOA2dC or FOXOA2dCmDBD dramatically repressed both hormone-independent and -dependent PGRA activity (Fig. 6C, lanes 4 and 5 compared respectively with lane 1). FOXOA2dN repressed hormone-dependent activity although this mutant retained an intact MAD (lane 6 compared with lane 1). However, the mutant DBD variant of FOXOA2dN (FOXOA2dN-mDBD) facilitated ligand-dependent and ligand-independent activities, similar to FOXOA3mDBD (lane 7 compared with lane 3). Thus, ligand-independent activation of PGRA by a DBD mutant occurs without the $\mathrm{N}$ terminus but not without the entire $\mathrm{C}$ terminus (lane 7 compared with lane 3 vs 5 compared with lane 3). These data localize the ligand-independent effects of FOXOA3-mDBD primarily to the $\mathrm{DBD}$ and a region between the $\mathrm{DBD}$ and the $\mathrm{MAD}$, probably the NID.

\section{The behavior of FOXOA3-mDBD is not merely an artifact created by a specific mutation in the DBD}

We next analyzed if the observed functions of FOXOA3$\mathrm{mDBD}$ and $-\mathrm{mDBD} / \mathrm{dMAD}$ represented more than a fortuitous gain of function arising from the H215R substitution. For this, we generated a FOXOA3 construct in which the $\mathrm{N}$ terminus was deleted through more than half of the DBD but residue H215 was left unchanged (FOXOA2FP). This mutant also stimulated PGRA activity in a ligand-independent manner (Fig. 6C, lane 8 compared with lane 3). These results provide evidence that the behavior of FOXOA3-mDBD is more than an artifact of the H215R substitution.

\section{FOXOA3 and FOXOA3-mDBD stimulate a PGRA mutant lacking the AF1 domain}

To address whether or not FOXOA3 could activate a transcriptionally defective PGRA lacking the AF1 
activation (Giangrande et al. 1997, Takimoto et al. 2003) domain but containing the DBD (C/D) and ligandbinding domains (E; Fig. 7A; schematic; PGRA-dA/B), the activity of PGRAdA/B was analyzed in the presence of FOXOA3 and FOXOA3mDBD. As shown in Fig. 7A, PGRA alone, but not PGRAdA/B, activated the GRE-luciferase construct (lanes 4 and 5 compared, respectively, to lane 1 ). Nevertheless, FOXOA3 enhanced ligand-dependent and FOXOA3-mDBD-stimulated ligand-independent activation of both PGRA and PGRAdA/B to a similar extent (lane 6 compared with lane 4 versus lane 7 compared with lane 5 ; lane 8 compared with lane 4 versus lane 9 compared with lane 5 respectively). Thus, FOXOA3 and FOXOA3mDBD activation of PGRA is not dependent on the AF1 domain. Rather, the FOXO factors appear capable of substituting for this domain.

Since PGRA and PGRB exert different functional activities in vivo, we next determined if FOXOA3 or its DBD mutant exhibited similar or different activities in the presence of PGRB (Fig. 7B). As in previous experiments, FOXOA3 enhanced the activity of liganded PGRA (lane 5 compared with lane 4) and the FOXOA3-DBD mutant enhanced ligand-independent activation of PGRA (lane 6). Although FOXOA3 did not enhance liganded PGRB (lane 8 compared with lane 7 ), the DBD mutant did enhance ligand-independent activation of PGRB (lane 9 ). When cells were co-transfected with PGRB lacking a functional DBD, neither FOXOA3 nor FOXOA3-DBD activated luciferase activity about that observed in cells without PGR vectors (lanes 10-12 compared with lanes 13 ). Thus, the ability of the FOXOA3-DBD mutant to enhance PGR activity is not isoform-specific, but does depend on the presence of PGR capable of binding to the GRE promoter region within the luciferase reporter construct.

\section{FOXO1a and PGRA functionally interact on the lgfbp promoter}

The mouse $I g f b p 1$ promoter, like the human promoter, is a known target of FOXO factors and PGRA and contains a FOXO response element (IRS) flanked by two consensus PREs known to bind PGRA (Gao et al. 1999, 2000; Fig. 8A). Furthermore, the Igfbpl gene is induced by FOXOA3 but not by its DBD mutant (Ramaswamy et al. 2002). Therefore, this promoter was selected as a potentially ideal system with which to test the effects of FOXOA3 and FOXOA3-mDBD on the activities of PGRA and PGRAdA/B on PRE sites within a natural promoter. Co-transfection analyses revealed that PGRA and PGRAdA/B exhibited little activity with or without ligand (Fig. 8B, compare lanes 4 and 9 respectively, with lane 1) indicating that the PRE sites were functionally weak. FOXOA3 and surprisingly FOXOA3-mDBD alone induced somewhat more activity (lanes 2 and 3 respectively, compared with lane 1). However, FOXOA3 robustly enhanced hormone-dependent and hormoneindependent activation of both PGRA and PGRAdA/B (lanes 5, 6 and 10, 11 respectively, compared with lanes 2 and 3). Since reporter activity was greater with FOXOA3 in the presence of PGRA-dA/B than with PGRA (lanes 10 and 11, compared with lanes 5 and 6 , respectively), the activation function-1 (AF-1) domain of PGRA may actually limit the ability of PGRA in this context. Like FOXOA3, the DBD mutant retained its ability to enhance unliganded PGRA. However, it failed to enhance liganddependent activity on the Igfbpl promoter (compare lanes 8 and 6) and was less potent than FOXOA3 in activating PGRAdA/B. These results indicate that the interactions of FOXOA3 and FOXOA3-mDBD with PGRA and PGRAdA/B differ on this promoter.

\section{FOXOA3 co-regulates PGRA in GC}

Since FOXOla is highly expressed in ovarian GC coordinantly with ERS1/2 and PGRA (Richards 2001, Richards et al. 2002a,b Sriraman et al. 2003), we explored the effect of FOXOla on PGRA activity in these cells (Fig. 9). As shown, reporter activity was negligible when vectors expressing FOXOA3, FOXOA3-mDBD, or FOXOA3-mNID were co-transfected into GC with the GRE-luciferase construct (Fig. 9A, lanes 2, 3 and 4 respectively). However, PGRA markedly stimulated reporter activity (lane 5 compared with lane 1 ). When FOXOA3 was co-transfected with PGRA, it reduced ligand-stimulated PGRA transactivation at $100 \mathrm{ng}$ (lane 7 compared with lane 5) but not at $10 \mathrm{ng}$ (lane 6 compared with lane 5), whereas co-transfection with FOXOA3-mDBD markedly enhanced basal and liganddependent activation by PGRA (lane 8 compared with lane 5). In contrast, FOXOA3-mNID significantly reduced ligand-induced activity by PGRA (lane 9 compared with lane 5). Thus, functional interactions of FOXOA3-mDBD and FOXO-NID with PGRA in GC are similar to those observed in COS cells, whereas FOXOA3 is less active and even slightly inhibitory.

When activation of the Igfbpl promoter was analyzed in GC, liganded PGRA induced the promoter (Fig. 9B, lane 4 compared with lane 1). Although FOXOA3 strongly enhanced ligand-dependent activation of the promoter by PGRA (lanes 5 and 6 compared with lane 4), FOXOA3-mDBD had no detectable effect on PGRA activity (lanes 7 and 8, compared with lane 4). Thus, the effects of PGRA and FOXOA3 but FOXOA3$\mathrm{mDBD}$ on the $\operatorname{Igfbp} 1$ promoter in GC were similar but much less robust than those observed in COS cells.

\section{Discussion}

This systematic analysis of how specific FOXOA1 mutants can interact functionally with PGRA and 
A GRE-Luc

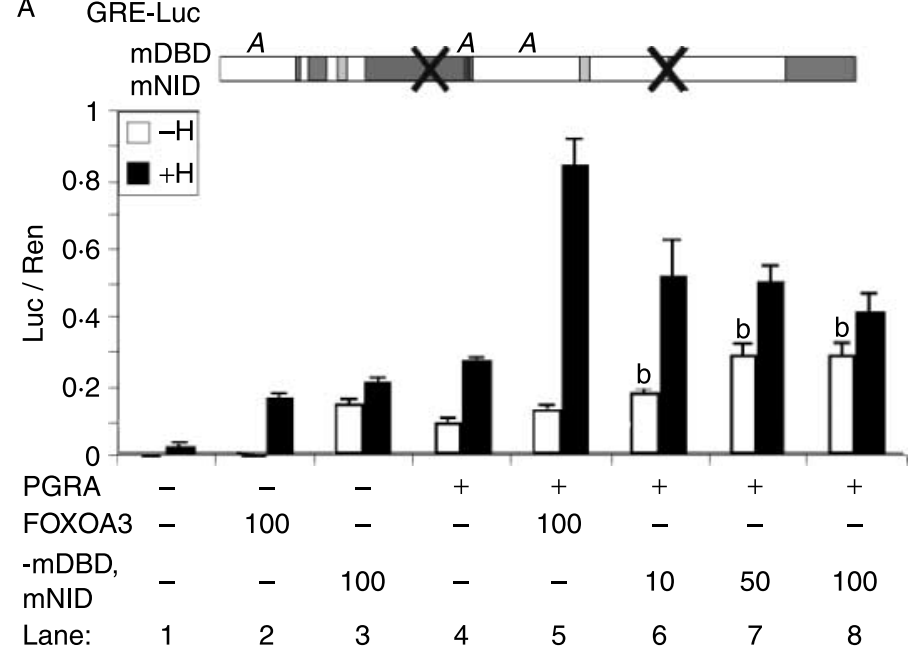

B
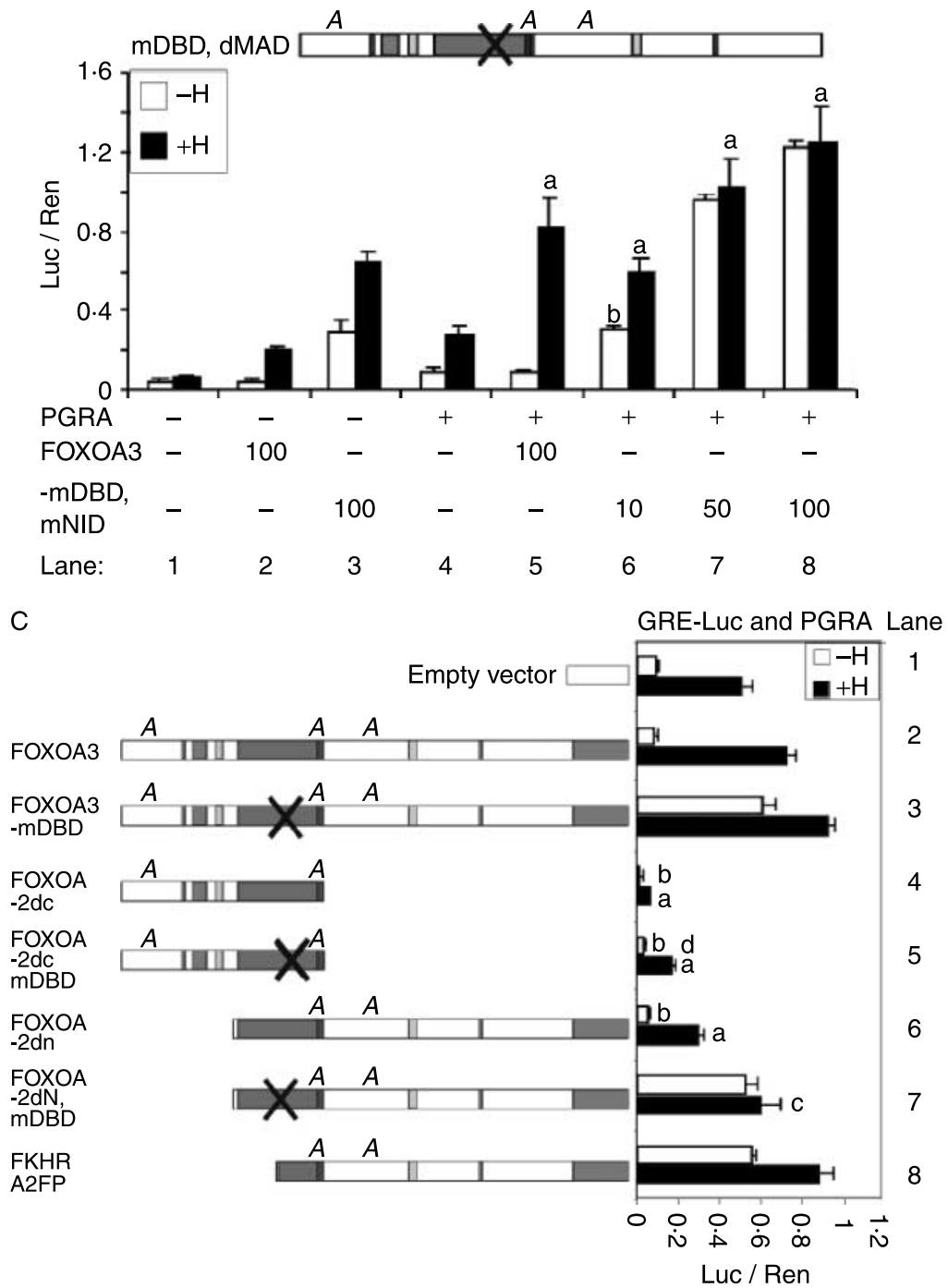
ESR1 on simple and more complex promoters provides several novel results. Specifically, we show that FOXOA3 enhances hormone-dependent (but not hormoneindependent) activation of PGRA on a PRE-responsive promoter and of ESR1 on an ERE-responsive reporter. These effects are dependent on both the time of exposure to hormone and the amount of FOXOA3 vector present. Although the NID LXXLL motif is conserved in FOXO family members and has been presumed to be critical for FOXOla interactions with nuclear hormone receptors (Zhao et al. 2001), our results document for the first time that mutation of this domain does not prevent FOXO binding to PGRA in a GST pull-down assay. However, since the FOXOA3mNID was less active than FOXOA3 in enhancing PGRA activation, it probably facilitates the recruitment of other key co-regulatory factors to the transcription complex. These results suggested that regions other than and in addition to the NID were critical for FOXOmediated transcriptional regulation of PGRA. Importantly, one of these other domains is the MAD, which we document is essential to potentiate FOXOA3 activation of PGRA on a GRE reporter. That an N-terminal truncation mutant of FOXOA3 (that retains the DBD) not only exhibits diminished activity on an IRS reporter but also shows reduced activation of PGRA activity indicate that the $\mathrm{N}$-terminal region also harbors functional sites, presumably those which recruit specific co-regulatory factors.

In striking contrast, the DNA-binding defective FOXOA3 modulated PGRA and ESR1 activities by mechanisms distinctly different from those of FOXOA3. Specifically, FOXOA3-mDBD markedly elevated not only ligand-dependent but also ligandindependent activities of these nuclear hormone receptors on their consensus promoter elements. This effect was observed not only in COS cells but also in ovarian GC. Moreover, the enhancing effect of FOXOA3-mDBD on PGRA activation of a GREpromoter persisted longer in the presence of hormone than does the effect of FOXOA3. Moreover, this distinct behavior of the DBD mutant occurred independently of the MAD, a region essential for FOXOA1 function on IRS containing promoters and for FOXOA3 activation of PGRA (Figs 1 and 2). This behavior also persisted in the DBD mutant lacking the N-terminal domain. It is difficult to believe that a mutant of FOXOA3 lacking these domains retains more than a small fraction of the transcriptional activity of FOXOA3. Thus, it appears that the ability of FOXOA3-mDBD to enhance PGRA and ERS1 activities on their consensus promoter sites is entirely independent of DNA binding and the MAD. The molecular mechanisms by which the H215R mutation alters FOXOA3 function could involve the unmasking of a co-regulator activity or the silencing of a repressor site within the DBD itself. Regardless of the mechanism through which FOXOA3-mDBD may operate, it is clear that the results of any experiment in which FOXOA3-mDBD is used as a negative control must be interpreted with caution. Our observations clearly reinforce previous findings that this form of FOXO1a is not transcriptionally inert (Ramaswamy et al. 2002). Rather our study demonstrates that, depending on promoter context, it can potently activate at least two nuclear hormone receptors.

We also show that FOXOA3 and FOXOA3-mDBD markedly stimulated a transcriptionally defective PGRA mutant lacking the AF1 activation domain (PGRdA/B), suggesting that the AF1 domain is not essential for FOXOA3 enhancement of PGRA on a GRE-driven reporter. However, the potency of FOXOA3 and the DBD mutant on the activities of PGRA and PGRAdA/B was promoter specific. When the Igfbpl promoter (that has an IRS flanked by two PREs) was analyzed in COS cells and GC, FOXOA3 was more potent than the FOXOA3 DBD mutant in activating PGRA and this effect of FOXOA3 was enhanced with PGRAdA/B. The basis for this switch in the relative potencies of FOXOA3 and its DBD mutant is not entirely clear, but probably depends on the ability of FOXOA3 (but not FOXO-mDBD) to bind the IRS within the Igfbpl promoter. In addition, since PGRA alone, with or without hormone, had only a minimal effect on the Igfbpl promoter, it appears that FOXOla is a much more potent regulator of this promoter and either recruits or stabilizes PGRA on the adjacent PREs or recruits other important regulatory factors that can also interact with PGRA. This was not anticipated in our selection of this promoter. Indeed, we selected the Igfbpl promoter as a model to confirm that although FOXOA3-mDBD would be unable to bind and activate this promoter, it would retain its enhancing effects on PGRA. That this was not observed suggests that other

Figure 6 Mutations of NID, MAD, and N-terminal and C-terminal deletions have different effects on the enhancement ability displayed by full-length FOXOA3 and FOXOA3-mDBD. COS cells were co-transfected as in Fig. 2 with a GRE reporter construct, a Renilla expression plasmid, a PGRA expression plasmid (where indicated in $A$ and $B$, in each case in $C$ ), and with expression plasmids in the amounts shown (ng/well) for the specified FOXO1a mutants. One and a half days later, the cells were treated for $4 \mathrm{~h}$ with vehicle (open bars) or R5020 (10 nM; solid bars). Luciferase assay data are presented as in Fig. 2. (A) 'b' indicates a significant difference from the $-\mathrm{H}$ value in lane 4. (B) ' $a$ ' and ' $b$ ' indicate a significant difference from the respective $+\mathrm{H}$ and $-\mathrm{H}$ values in lane 4. (C) ' $a$ ' and 'b' indicate a significant difference from the respective $+\mathrm{H}$ and $-\mathrm{H}$ values in lane 1, and 'c' and 'd' indicate a significant difference from the respective $+\mathrm{H}$ and $\mathrm{H}$ values in lane 3. 
Igfbp1 promoter regions and/or other interacting factors potently modify the activity of FOXOA3-mDBD.

Also surprising was the enhanced effect of FOXOA3 with the AF-1 PGRA mutant on the Igfbpl promoter.
This result indicates that the AF-1 region of PGRA has the potential to mediate negative effects on FOXOA3PGRA functions. This may provide a molecular basis for the observed repressive effects of PGRA and ERS1 on

A

GRE-Luc

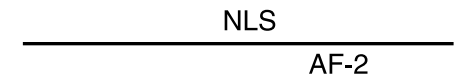

\begin{tabular}{cccc|} 
& AF-1 & DBD & LBD \\
\cline { 2 - 3 } PGRA & C $B$ & E \\
\cline { 2 - 3 }
\end{tabular}

\begin{tabular}{|l|lll|l|}
\cline { 3 - 4 } \multicolumn{1}{c|}{ PGRA-dA/B } & C & $D$ & E \\
\hline PGRB & A/B & C & $D$ & D \\
\hline
\end{tabular}

\begin{tabular}{|l|l|l|l|}
\hline mPGRB & $\mathrm{A} / \mathrm{B}$ & $\mathrm{XX}$ & $\mathrm{E}$ \\
\hline
\end{tabular}

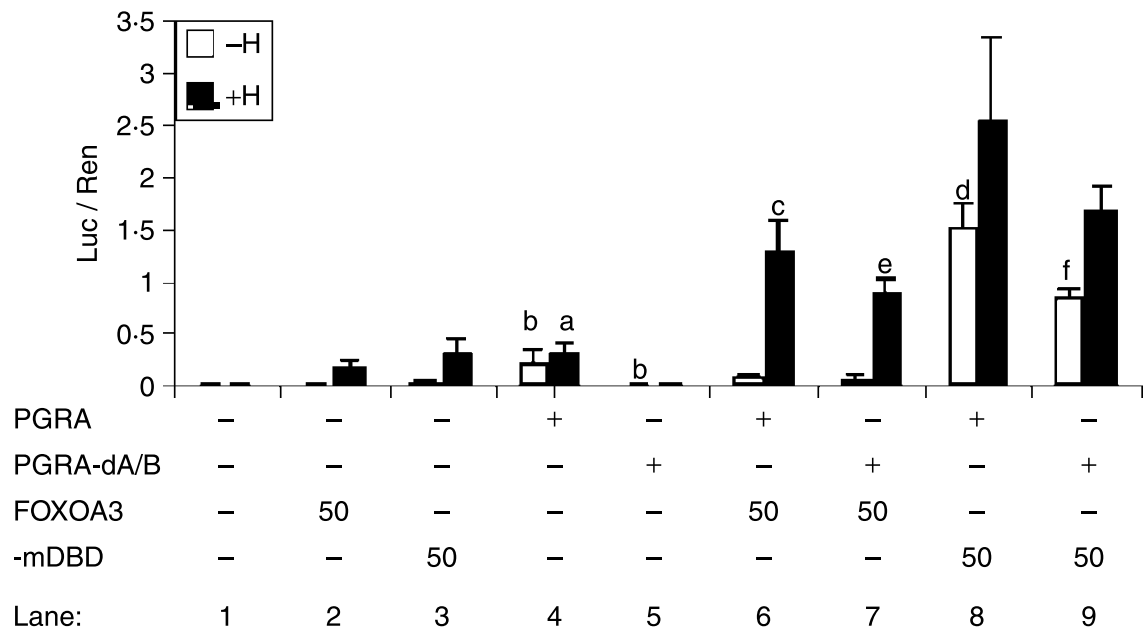

B

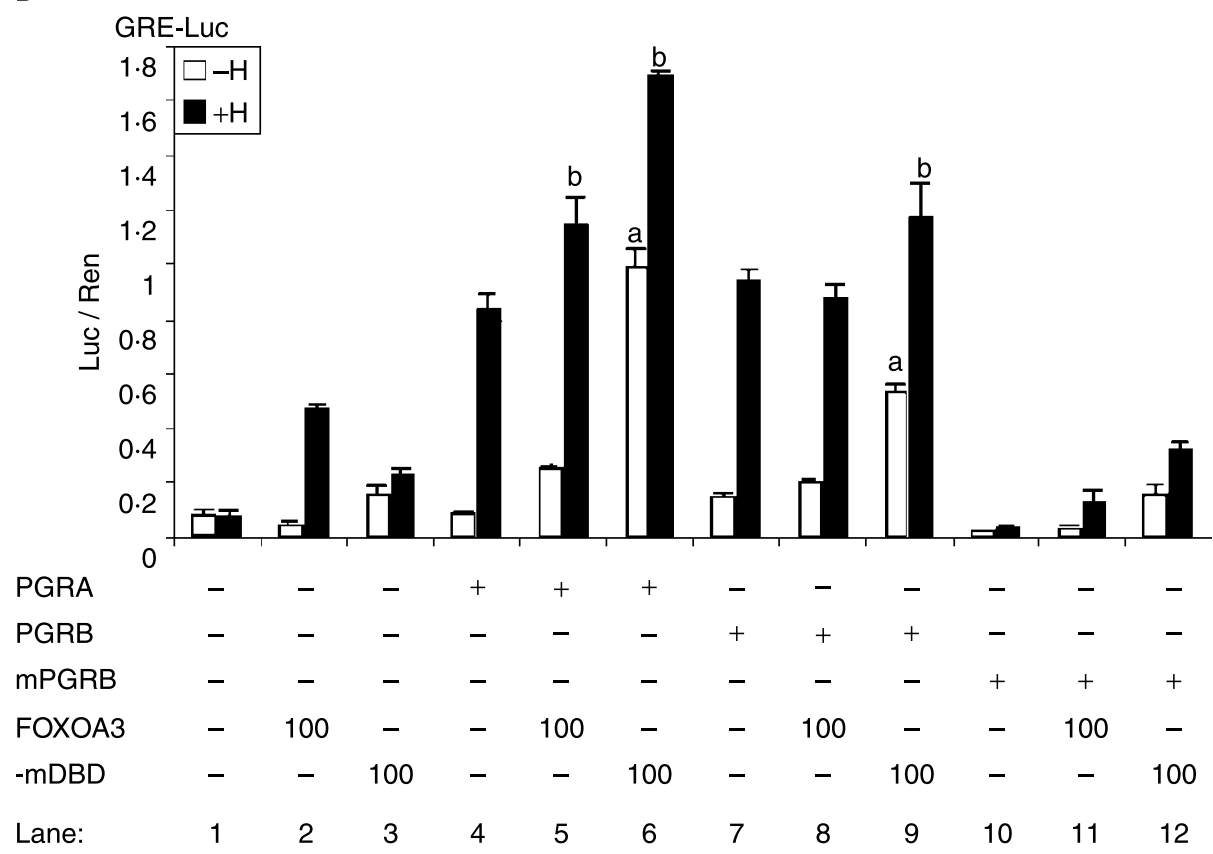


A

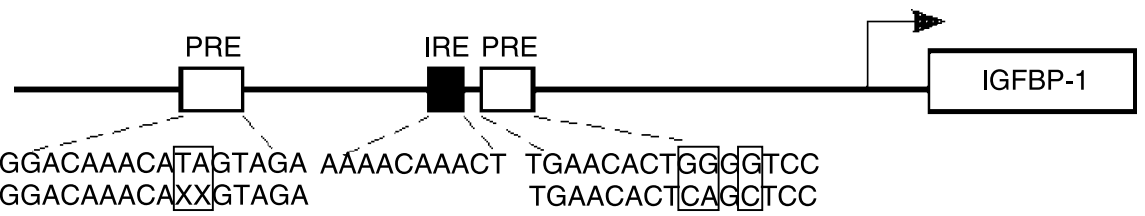

B

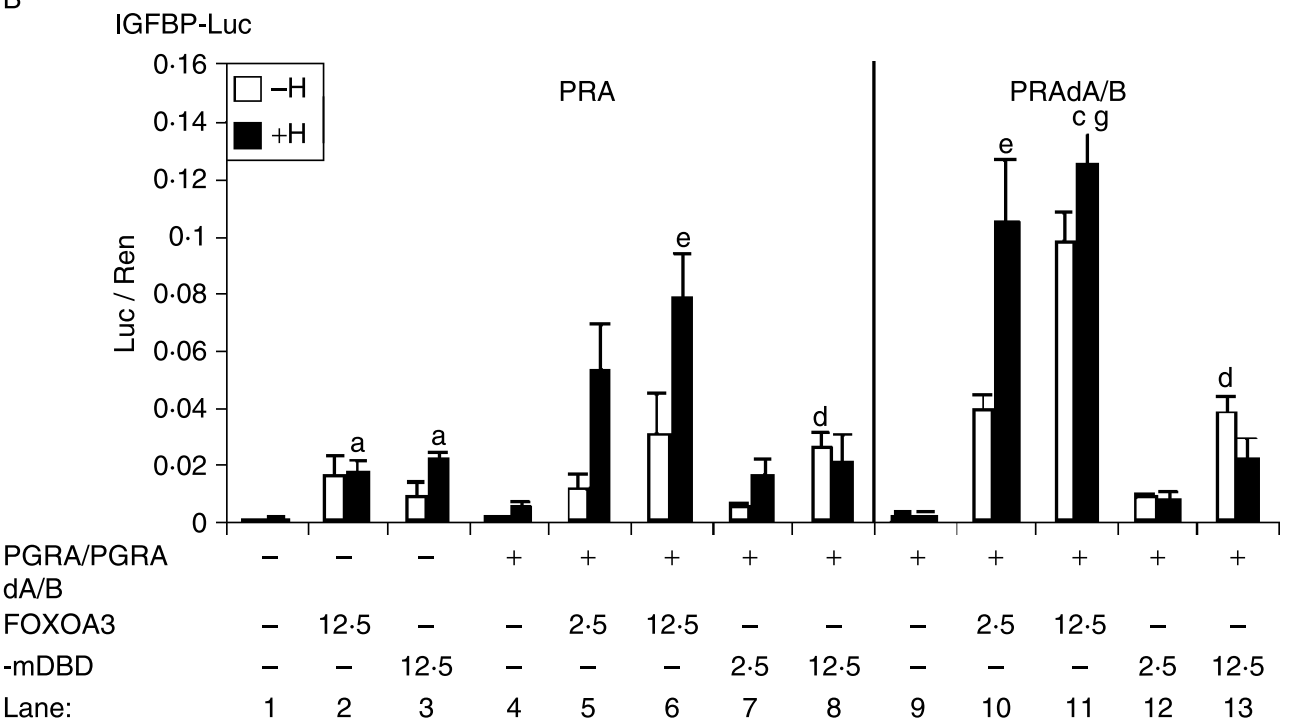

Figure 8 FOXOA3 and PGRA functionally interact on an IGFBP-1 promoter-reporter construct, but FOXO1a induces the reporter more strongly with PGRAdA/B than with wild-type PGRA. (A) Schematic of the mouse and human IGFBP1 promoters showing conserved IRS and PRE sites. (B) COS cells were co-transfected with the IGFBP1 promoter-Luc vector and either PGRA (lanes 2-8) or PGRAdA/B (lanes 913) and were treated $36 \mathrm{~h}$ later with R5020 for $4 \mathrm{~h}$. Luciferase assay data are presented as in Fig. 2 . (B) ' $a$ ' indicates a significant difference from the $+\mathrm{H}$ value in lane 1, ' $c$ ' indicates a significant difference from the + $H$ value in lane 2, ' $d$ ' indicates a significant difference from the $-H$ value in lane 3 , ' $e$ ' indicates a significant difference from the $+\mathrm{H}$ value in lane 5 , and ' $\mathrm{g}$ ' indicates a significant difference from the $+\mathrm{H}$ value in lane 6 .

the FOXO activation of an IRS promoter (data not shown; (Schuur et al. 2001)). PGRA and ERS1 can act as co-regulatory molecules that enhance the functional activity of other transcription factors, such as SP1 and AP1 (McKenna \& O'Malley 2002, Doyle et al. 2004, Baron et al. 2007 and references therein). Therefore, the cumulative effect of PGRA and FOXOla on the complex Igfbpl promoter may reflect the sum of these two opposing activities, positive actions of FOXOA3 with PGRA on the PRE site(s) and negative regulation of FOXOA3 on the IRS site. Other promoter regions and factors are also likely to impact PGRA and FOXOA3 activity on the $I g f b p 1$ promoter. These other factors and regions appear to have greater impact on the activation of the Igfbpl promoter in GC than in COS cells.

Determining specific functional domains of FOXO1a is important for understanding how this factor impacts gene expression in FOXOla-expressing cells, including ovarian GC. Although FOXO3a null mice are infertile and exhibit accelerated follicular development (Castrillon et al. 2003, Hosaka et al. 2004). FOXO1a null mice are embryonically lethal partly due to vascular defects (Furuyama et al. 2004, Potente et al. 2005), therefore relatively little is known about how this FOXO factor impacts specific GC functions in vivo (Richards et al. 2002b,

Figure 7 The AF1 domain of PGRA plays no part in the action of FOXOA3 or FOXOA3-mDBD on PGRA activity and PGRB also interacts with FOXOA3-mDBD. COS cells were co-transfected with a PRE/GRE-luciferase reporter plasmid and a constitutively active Renilla expression vector as described in the Materials and methods. Also included in the transfections were $10 \mathrm{ng} /$ well expression constructs for wild-type PGRA or a mutant of PGRA lacking the AF-1 domain (A) PGRB or a mutant of PGRB lacking the DBD (B; see schematic above graph) and the indicated amounts of expression vector for FOXOA3 or FOXOA3-mDBD. After a day and a half, the cells were provided a $4 \mathrm{~h}$ treatment with R5020 (10 nM; solid bars) or vehicle (open bars) and then lysed. Luciferase assay data are presented as in Fig. 2. (A) 'a' and ' $b$ ' indicate a significant difference from the respective $+\mathrm{H}$ and $-\mathrm{H}$ values in lane 1 , ' $c$ ' and ' $d$ ' indicate a significant difference from the respective $+\mathrm{H}$ and $-\mathrm{H}$ values in lane 4 , and ' $\mathrm{e}$ ' and ' $\mathrm{f}$ ' indicate a significant difference from the respective $+\mathrm{H}$ and $-\mathrm{H}$ values in lane 5 . (B) ' $a$ ' indicates a significant difference from $-\mathrm{H}$ values in lanes 5 and 8 , 'b' indicates a significant difference from $+\mathrm{H}$ in lanes 4 and 7. 
A

$$
\text { GRE-LUC }
$$

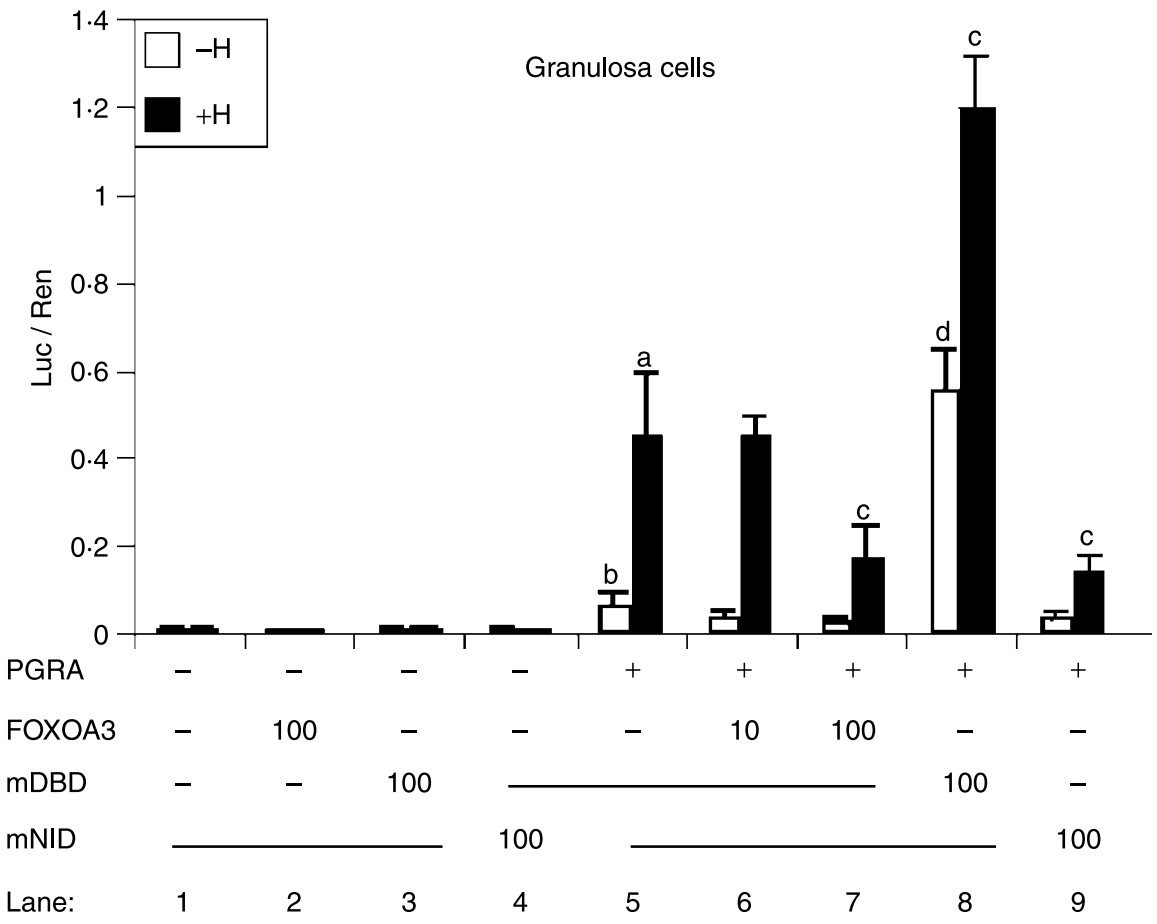

B

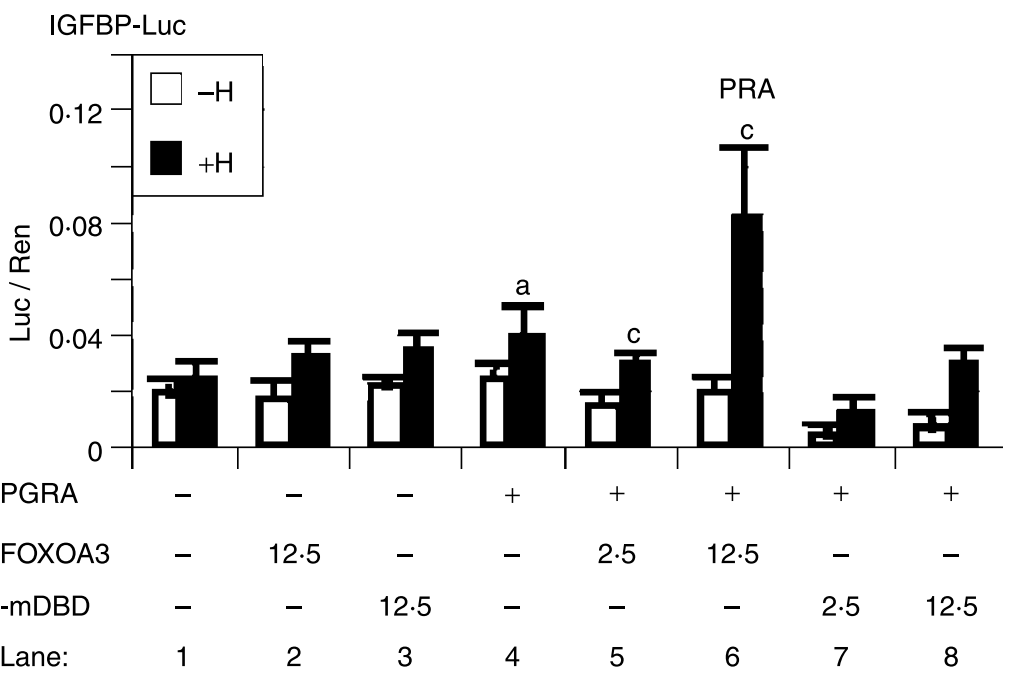

Figure 9 The effects of FOXOA3 and FOXOA3-mDBD on PGRA activity are cell-type and promoter-specific. Granulosa cells from the ovaries of estrogen-primed rats were co-transfected, as also described in the Materials and methods, with a PRE/GRE-luciferase reporter plasmid (A) or a mouse IGFBP-1 reporter plasmid (B), and a constitutively active Renilla expression vector. Also included, at $10 \mathrm{ng} /$ well with the GRE reporter or $2.5 \mathrm{ng} /$ well with the IGFBP-1 construct, was an expression construct for wild-type PGRA. Further included was an expression vector for one or another of the indicated FOXO1a mutants, in the amounts shown above (ng/well). Between 12 and $16 \mathrm{~h}$ after transfection, the cells were given R5020 (10 nM; solid bars) or vehicle (open bars), and $4 \mathrm{~h}$. Luciferase assay data are presented as in Fig. 2. (A) 'a' and 'b' indicate a significant difference from the respective $+\mathrm{H}$ and $-\mathrm{H}$ values in lane 1, and ' $\mathrm{C}$ ' and ' $\mathrm{d}$ ' indicate a significant difference from the respective $+\mathrm{H}$ and $-\mathrm{H}$ values in lane 5. (B) ' $a$ ' indicates a significant difference from the $+\mathrm{H}$ value in lane 1, and ' $\mathrm{C}$ ' indicates a significant difference from the $+\mathrm{H}$ value in lane 4. 
Cunningham et al. 2004, Park et al. 2005). The results described herein provide some basic information for guiding the interpretation of further studies designed to delineate the complex mechanisms by which FOXOla regulates gene expression in a variety of cells. Specifically, our observations document that the constitutively active A3 form of FOXO1a acts as a potent co-regulatory molecule to modify the transcriptional activity of PGRA on a GRE-responsive promoter and on the $I g f b p 1$ promoter and that the effects of FOXOA3 are partly dependent on an intact NID, MAD, and N-terminal domain. Although the effects of FOXOA3 on PGRA activity are time-, cell-, and promoter-specific, in most contexts the effects were positive and ligand-dependent. Moreover, our study demonstrates that although the DNA-binding defective form of FOXOA3 is inactive on IRScontaining promoter elements, it is a functional protein capable of exerting co-regulatory activity on nuclear hormone receptors. Specifically, FOXOA3mDBD potently activated (on consensus promoter elements) at least two nuclear hormone receptors independently of ligand and its own MAD and to a lesser extent the LXXLL NID on their consensus promoters. In this regard, these mutants have the potential to be novel tools to identify the targets of FOXOla action that are effected independently of FOXOla DNA binding and its MAD. Thus, future comparisons of the effects of FOXOA3 and FOXOA3 DBD mutants on endogenous genes in different cell types should permit the identification of new FOXO targets and functions that occur independently of DNA-binding activity.

\section{Acknowledgements}

The authors thank Drs Terry Untermann (University of Illinois at Chicago), William Sellers (Harvard Medical School), Eric D Tang (University of Michigan), V Craig Jordon (Northwestern University Feinberg School of Medicine), as well as Rainer Lanz and Neill Mckenna (Baylor College of Medicine; BCM) who generously provided vectors that have been used and modified for use in these studies. The authors also thank the Tissue Core Facility (Department of Molecular and Cellular Biology, BCM) for providing COS-1 cells and tissue culture reagents essential to this study, and Dr Dean Edwards of the Protein Core laboratory for the PGRAGST and Dr Alan R Davis from the Core Vector Laboratory for providing reagents and expertise used in generating the adenoviral vectors. The authors declare that there is no conflict of interest that would prejudice the impartiality of this scientific work.

\section{Funding}

The study was supported by NIH-HD-16272 (JSR), CA57539 (NLW) and the Spanish Ministry of Education, Culture and Sport and Autonomous Community of Canary Islands (IH-G and IG-R).

\section{References}

Accili D \& Arden KC 2004 FoxOs at the crossroads of cellular metabolism, differentiation and transformation. Cell 117 421-426.

Baron S, Escande A, Alberola G, Bystricky K, Balaguer P \& Richard-Foy $\mathrm{H} 2007$ Estrogen recetpor a and the AP1 complex coorperate during IGF-1-induced transcriptional activation of the $p S 2 / T F F 1$ gene. Journal of Biological Chemistry 282 11732-11741.

Bennicelli JL, Fredericks WJ, Wilson RB, Rauscher FJI \& Barr FG 1995 Wild-type PAX3 protein and PAX3-FKHR fusion protein of alveolar rhabdomyosarcoma contain potent, structurally distinct transcriptional activation domains. Oncogene 11 119-130.

Brunet A, Bonni A, Zigmond MJ, Lin MZ, Juo P, Hu LS, Anderson MJ, Arden KC, Blenis J, Greenberg ME et al. 1999 Akt promotes cell survival by phosphorylating and inhibiting a forkhead transcription factor. Cell 96 857-868.

Brunet A, Park J, Tran H, Hu LS, Hemmings BA \& Greenberg ME 2001 Protein kinase SGK mediates survival signals by phosphorylating the forkhead transcription factor FKHRL1 (FOXO3a). Molecular and Cellular Biology 21 952-965.

Burgering BM \& Kops GJ 2002 Cell cycle and death control: long live Forkheads. Trends in Biochemical Science 27 352-360.

Castrillon DH, Miao L, Kollipara R, Horner JW \& DePinho RA 2003 Suppression of ovarian follicle activation in mice by the transcription factor Foxo3a. Science 301 215-218.

Cunningham MA, Zhu Q \& Hammond JM 2004 FoxOla can alter cell cycle progression by regulating the nuclear localization of p27kip in granulosa cells. Molecular Endocrinology 18 1756-1767.

Doyle KMH, Russell DL, Sriraman V \& Richards JS 2004 Coordinate transactivation of the ADAMTS-1 gene by luteinizing hormone and progesterone receptor. Molecular Endocrinology 18 2463-2478.

Essers MA, de Vries-Smits LM, Barker N, Polderman PE, Burgering BM \& Korswagen HC 2005 Functional interaciton bewteen betacatenin and FOXO in oxidative stress signaling. Science $\mathbf{3 0 8}$ 1181-1184.

Fitzpatrick SL \& Richards JS 1991 Regulation of cytochrome P450 aromatase messenger ribonucleic acid and activity by steroids and gonadotropins in rat granulosa cells. Endocrinology 129 1452-1462.

Furuyama T, Kitayama K, Shimoda Y, Ogawa M, Sone K, Yoshida-Araki K, Hisatsune H, Nishikawa S-i, Nakayama K, Nakayama K et al. 2004 Abnormal angiogenesis in Foxol (Fkhr)-deficient mice. Journal of Biological Chemistry 279 34741-34749.

Gao J, Mazella J, Suwanichkul AM, Powell DR \& Tseng L 1999 Activation of the insulin-like growth factor binding protein 1 promoter by progesterone receptor in decidualized human endometrial cells. Molecular and Cellular Endocrinology 153 11-17.

Gao J, Mazella J, Tang M \& Tseng L 2000 Ligand-activated progesterone receptor isoform hPR-A is a stronger transactivator than hPR-B for the e xpression of the insulin-like growth factor binding protein-1 (IGFBP-1) in humman endometrial cells. Molecular Endocrinology 14 1954-1961.

Giangrande PH, Pollio G \& McDonnell DP 1997 Mapping and characterization of the functional domains responsible for the differential activity of the $\mathrm{A}$ and $\mathrm{B}$ form of the human progesterone receptor. Journal of Biological Chemistry 272 32889-32900.

Gonzalez-Robayna IJ, Falender AE, Ochsner S, Firestone GL \& Richards JS 2000 FSH stimulates phosphorylation and activation of 
protein kinase B (PKB/Akt) and serum and glucocorticoid-induced kinase (Sgk): evidence for A-kinase independent signaling in granulosa cells. Molecular Endocrinology 14 1283-1300.

Hang H, Muddiman DC \& Tindall DJ 2004 Androgens negatively regualte forkhead transcription factor FKHR (FOXO1) through a proteolytic mechanism in prostate cancer cells. Journal of Biological Chemistry 279 13866-13877.

Heery DM, Hoare S, Hussain S, Parker MG \& Sheppard H 2001 Core LXXLL motif sequences in CREB-binding protein SRC1 and RIP140 define affinity and selectivity for steroid and retinoid receptors. Journal of Biological Chemistry 276 6695-6702.

Van der Heide LP \& Smidt MP 2005 Regulation of FoxO activity by CBP/P300-mediated acetylation. Trends in Biochemical Science 30 $81-86$.

Van der Heide LP, Hoekman MF \& Smidt MP 2005 The ins and outs of FoxO shuttling: mechanisms of FoxO translocation and transcriptional regulation. Biochemical Journal 380 297-309.

Hirota K, Daitoku H, Matsuzaki H, Araya N, Yamagata K, Asada S, Sugaya T \& Fukamizu A 2003 Hepatocyte nuclear factor 4 is a novel downstream target of insulin via FKHR as a signal-regulated transcriptional inhibitor. Journal of Biological Chemistry 278 13056-13060.

Hosaka T, Biggs WH, Tieu D, Boyer AD, Varki NM, Cavenee WK \& Arden KC 2004 Disruption of forkhead transcription factor (FOXO) family members in mice reveals their functional diversification. PNAS 101 2975-2980.

Kenyon C 2005 The plasticity of aging: insights from long-lived mutants. Cell 120 449-480.

Kim JJ, Buzzio OL, Li S \& Lu Z 2005 Role of FOXO1A in the regulation of insulin-like growth factor binding protein-1 in human endometrial cells; interaction with progesterone receptor. Biology of Reproduction 73 833-839.

Kodama S, Koike C, Negishi M \& Yamamoto Y 2004 Nuclear receptors $C A R$ and PXR cross talk with FOXO1 to regulate genes that encode drug-metabolizing and gluconeogenic enzymes. Molecular and Cellular Biology 24 7931-7940.

Kops GJPL, De Ruiter ND, De Vries-Smits AMM, Powell DR, Bos JL \& Burgering BMTh 1999 Direct control of the Forkhead transcription factor AFX by protein kinase B. Nature 398 630-634.

Kops GJPL, Medema RH, Glassford J, Essers MAG, Dijkers PF, Coffer PJ, Lam EW-F \& Burgering BMT 2002 Control of cell cycle exit and entry by protein kinase B-regualted forkhead transcription factors. Molecular and Cellular Biology 22 2025-2036.

Li P, Lee H, Guo S, Unterman TG, Jenster G \& Bai W 2003 AKTindependent protection of prostate cancer cells from apoptosis mediated through complex formation between the androgen receptor and FKHR. Molecular and Cellular Biology 23 104-118.

McKenna NJ \& O'Malley BW 2002 Combinatorial control of gene expression by nuclear receptors and coregulators. Cell 108 465-474.

Medema RH, Kops GJP, Bos JL \& Burgering BMT 2000 AFX-like forkhead transcription factors mediate cell cycle regulation by Ras and PKB through $\mathrm{p} 27^{\mathrm{KIP} 1}$. Nature 404 782-787.

Nakae J, Kitamura T, Ogawa W, Kasuga M \& Accili D 2001 Insulin regulation of gene expression through the forkhead transcription factor Foxol (Fkhr) requires kinases distinct from Akt. Biochemistry $4011768-11776$.

Park Y, Maizels ET, Feiger ZJ, Alam H, Peters CA, Woodruff TK, Unterman TG, Lee EJ, Jameson JL, Hunzicker-Dunn M et al. 2005 Induction of cyclin D2 in rat granulosa cells requires FSHdependent relief from FOXO1 repression coupled with positive signals from Smad. Journal of Biological Chemistry 280 9135-9148.

Potente M, Urbich C, Sasaki K-i, Hofmann WK, Heeschen C, Aicher A, Kollipara R, DePinho RA, Zeiher AM \& Dimmeler S 2005 Involvement of Foxo transcription factors in angiogenesis and postnatal neovascularization. Journal of Clinical Investigation 115 2382-2392.
Prowse DM, Bolgan L, Molnar L \& Dotto GP 1997 Involvement of the Sp3 transcription factor in induction of p21CIP1/KIP1 in keratinocyte differentiation. Journal of Biological Chemistry 272 1308-1314.

Puigserver P, Wu Z, Park CW, Graves R, Wright M \& Speigelman BM 1998 A cold-inducible coactivator of nuclear receptors linke to adaptive thermogenesis. Cell $\mathbf{9 2}$ 829-839.

Puigserver P, Rhee J, Donovan J, Walkey CJ, Yoon JC, Oriente F, Kitamura Y, Altomonte J, Dong H, Accili D et al. 2003 Insulinregulated hepatic gluconeogenesis through FOXO1-PGC1 alpha interactions. Nature 423 550-555.

Ramaswamy S, Nakamura N, Sansal I, Bergeron L \& Sellers WR 2002 A novel mechanism of gene regulation and tumor suppression by transcription factor FKHR. Cancer Cell 2 81-91.

Richards JS, Ochsner S, Russell DL, Falender AE, Hsieh MN, Doyle KH \& Sharma SC 2002a Novel signaling pathways that control follicular growth and ovulation. Recent Progress in Hormone Research $\mathbf{5 7}$ 57195-57220.

Richards JS, Sharma SC, Falender AE \& Lo YH $2002 b$ Expression of FKHR, FKHRL1 and AFX genes in the rodent ovary: evidence for regulation by IGF-1, estrogen and the gonadotropins. Molecular Endocrinology 17 520-533.

Richards JS 2001 New signaling pathways for hormones and cyclic adenosine $3^{\prime}, 5^{\prime}$-monophosphate action in endocrine cells. Molecular Endocrinology 15 209-218.

Schuur ER, Loktev AV, Sharma M, Sun Z, Roth RA \& Weigel RJ 2001 Ligand-dependent interaction of estrogen receptor-a with FKHR. Journal of Biological Chemistry 276 33554-33560.

Seoane J, Le H-V, Shen L, Anderson SA \& Massague J 2004 Integration of Smad and Forkhead pathwyas in the control of neuroepithelial and glioblastoma cell proliferation. Cell 117 211-223.

Shi F \& LaPolt PS 2003 Relationship between FoxO1 protein levels and follicular development, atresia, and luteinization in the rat ovary. Journal of Endocrinology 179 195-203.

Sriraman V, Sharma SC \& Richards JS 2003 Transactivation of the progesterone receptor gene in granulosa cells: evidence that $\mathrm{Sp1} / \mathrm{Sp} 3$ binding sites in the proximal promoter play a key role in luteinizing hormone inducibility. Molecular Endocrinology 17 436-449.

Sriraman V, Lohmann S, Mulders S \& Richards JS 2005 Cyclic guanosine $5^{\prime}$-monophosphate-dependent protein kinase II is induced by luteinizing hormone and progesterone receptordependent mechanisms in granulosa cells and cumulus oocyte complexes of ovulating follicles. Molecular Endocrinology 20 348-361.

Takimoto GS, Tung L, Abdel-Hafiz H, Abel MG, Sartorious CA, Richer JK, Jacobsen BM, Bain DL \& Horwitz KB 2003 Functional properties of the N-terminal region of the progesterone receptors and their mechanistic relationship to structure. Journal of Steroid Biochemistry and Molecular Biology 85 209-219.

Tang ED, Nunez G, Barr FG \& Guan KL 1999 Negative regulation of the forkhead transcription factor FKHR by Akt. Journal of Biological Chemistry 274 16741-16746.

Zhao HH, Herrera RF, Coronado-Heinsohn E, Yang MC, LudesMeyers JH, Seybold-Tilson KJ, Nawaz Z, Yee D, Barr FG, Diab SG et al. 2001 Forkhead homologue in rhabdomyosarcoma functions as a bifunctional nuclear hormone receptor-interacting protein with coactivator and corepressor functions. Journal of Biological Chemistry 276 27907-27912.

Received in final form 21 March 2007

Accepted 12 April 2007

Made available online as an Accepted Preprint 18 April 2007 